\title{
BIK drives an aggressive breast cancer phenotype through sublethal apoptosis and predicts poor prognosis of ER-positive breast cancer
}

Vrajesh Pandya', John Maringa Githaka', Namrata Patel', Richard Veldhoen $\mathbb{D}^{1}$, Judith Hugh², Sambasivarao Damaraju², Todd McMullen ${ }^{3}$, John Mackey ${ }^{4}$ and Ing Swie Goping ${ }^{1,4}$

\begin{abstract}
Apoptosis is fundamental to normal animal development and is the target for many anticancer therapies. Recent studies have explored the consequences of "failed apoptosis" where the apoptotic program is initiated but does not go to completion and does not cause cell death. Nevertheless, this failed apoptosis induces DNA double-strand breaks generating mutations that facilitate tumorigenesis. Whether failed apoptosis is relevant to clinical disease is unknown. $\mathrm{BCL}-2$ interacting killer (BIK) is a stress-induced $\mathrm{BH} 3$-only protein that stimulates apoptosis in response to hormone and growth factor deprivation, hypoxia, and genomic stress. It was unclear whether BIK promotes or suppresses tumor survival within the context of breast cancer. We investigated this and show that BIK induces failed apoptosis with limited caspase activation and genomic damage in the absence of extensive cell death. Surviving cells acquire aggressive phenotypes characterized by enrichment of cancer stem-like cells, increased motility and increased clonogenic survival. Furthermore, by examining six independent cohorts of patients (total $n=969$ ), we discovered that high BIK mRNA and protein levels predicted clinical relapse of Estrogen receptor (ER)-positive cancers, which account for almost $70 \%$ of all breast cancers diagnosed but had no predictive value for hormone receptor-negative (triplenegative) patients. Thus, this study identifies BIK as a biomarker for tumor recurrence of ER-positive patients and provides a potential mechanism whereby failed apoptosis contributes to cancer aggression.
\end{abstract}

\section{Introduction}

Apoptosis is a cell death program with tumorsuppressor activities. Inhibition of apoptosis causes cancer, and this was first identified in B-cell lymphomas driven by the antiapoptotic protein BCL-2 $2^{1,2}$. Biological insights into this protein family led to the development of BCL-2 homology domain (BH3) mimetics that inhibit BCL-2 antiapoptotic activities, to initiate the cascade of mitochondrial outer membrane permeabilization (MOMP), caspase activation, and cell death ${ }^{3,4}$. In 2016,

\footnotetext{
Correspondence: Ing Swie Goping (igoping@ualberta.ca)

${ }^{1}$ Department of Biochemistry, University of Alberta, Edmonton, AB T6G 2H7,

Canada

${ }^{2}$ Department of Lab Medicine and Pathology, University of Alberta, Edmonton,

AB T6G 2H7, Canada

Full list of author information is available at the end of the article

Edited by K. Sarosiek
}

ABT-199/Venetoclax attained breakthrough drug designation from the FDA for the treatment of leukemia ${ }^{5}$ and is in clinical testing for other cancers. Hence, apoptosis facilitates tumor cell death and cancer control. Paradoxically, antiapoptotic BCL-2 protein levels are prognostic for favorable outcomes in breast cancer $^{6-8}$ suggesting that attenuated apoptosis limits cancer progression. In line with this, recent studies have shown that low levels of apoptosis are oncogenic ${ }^{9-11}$. Noncancerous cultured cells that were exposed to radiation, chemotherapeutic drugs or the $\mathrm{BH} 3$ mimetic ABT-737 became transformed ${ }^{10-12}$. Mechanistically, this "failed apoptosis" stimulated the apoptotic DNases CAD and EndoG that induced DNA double-strand breaks (DSB) leading to genomic instability, and oncogenesis ${ }^{9-14}$. Thus, incompletely executed apoptosis has tumor-promoting

\section{(c) The Author(s) 2020}

(c) (i) Open Access This article is licensed under a Creative Commons Attribution 4.0 International License, which permits use, sharing, adaptation, distribution and reproduction cc) in any medium or format, as long as you give appropriate credit to the original author(s) and the source, provide a link to the Creative Commons license, and indicate if changes were made. The images or other third party material in this article are included in the article's Creative Commons license, unless indicated otherwise in a credit line to the material. If material is not included in the article's Creative Commons license and your intended use is not permitted by statutory regulation or exceeds the permitted use, you will need to obtain permission directly from the copyright holder. To view a copy of this license, visit http://creativecommons.org/licenses/by/4.0/. 


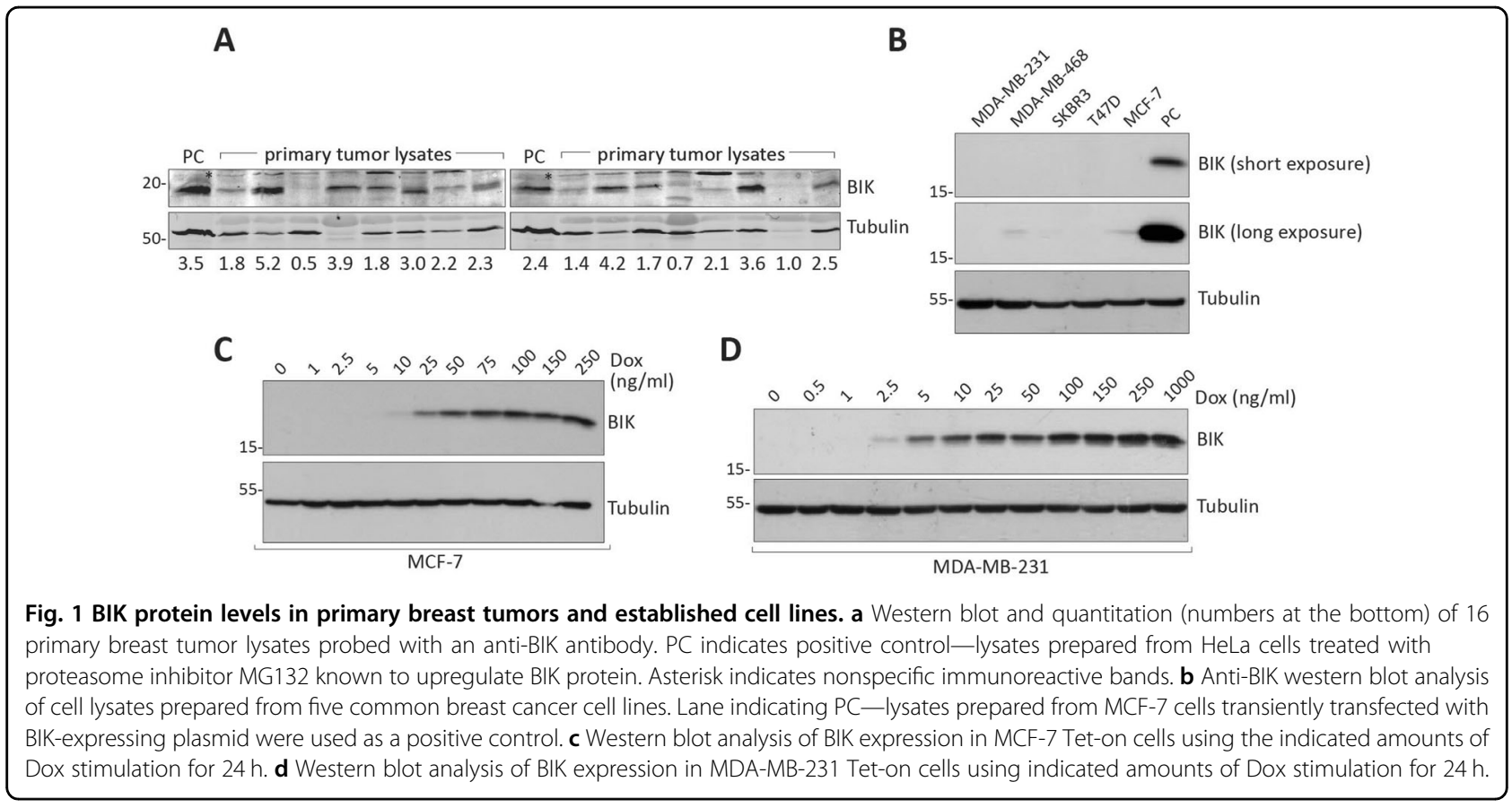

consequences in experimental model systems, although the relevance of this process to clinical disease is not clear.

BCL-2 interacting killer (BIK) is a proapoptotic BH3only member of the BCL-2 family and is prognostic for relapse and decreased overall survival of breast cancer ${ }^{15}$. This suggests that BIK may induce inefficient apoptosis within the context of clinical disease. Here we show that BIK expression in breast cancer cell lines activates caspases and induces genomic damage through caspaseactivated DNase (CAD). Despite caspase activation, apoptotic cell death is limited, and the resulting cell progeny show aggressive cell properties. Importantly, BIK expression is induced in response to the blockade of estrogen signaling in ER-positive cells ${ }^{16-18}$ suggesting that BIK may be specifically relevant to ER-positive breast cancer. In line with this, BIK elevation in ER-positive breast cancer patients is associated with increased recurrence and mortality but was not significantly prognostic for hormone receptor-negative patients. Thus BIKmediated inefficient apoptosis facilitates cellular evolution and identifies a potential new molecular mechanism for recurrence in a subset of breast cancers.

\section{Results}

\section{BIK can activate the apoptotic pathway while causing minimal cell death}

High levels of BIK in breast cancer tumors are prognostic for poor patient outcomes ${ }^{15}$. Since apoptosis is oncogenic when not fully executed in cell-based models ${ }^{9-12}$, we reasoned that BIK accelerated tumor evolution and disease relapse through failed apoptosis. The expression of BIK in tissues and cell lines is variable and is regulated in response to stressors, such as hormone and growth factor withdrawal, hypoxia, and genomic damage ${ }^{17,19-23}$. We therefore first assessed BIK protein levels from snapfrozen primary breast tumor samples and observed that the majority $(\sim 80 \%)$ of the samples had detectable BIK levels of differing intensity (Fig. 1a). In contrast, established breast cancer cell lines showed barely detectable levels of BIK (Fig. 1b), likely related to the fact that tumorassociated stressors are absent in cell-culture conditions ${ }^{16,23-25}$. In support of this, suppression of estrogen signaling by tamoxifen caused a dose-dependent increase in BIK levels (Supplementary Fig. 1A), confirming the existing ability of cells to induce BIK expression. To investigate BIK autonomous effects on cellular growth properties in the absence of the pleiotropic effects of stressors, we generated doxycycline (Dox)-inducible BIK expression in the breast carcinoma cell lines MCF-7 and MDA-MB-231 (Fig. 1c and d), as representatives of ERpositive and triple-negative breast cancer (TNBC) subtypes, respectively. BIK induction was tightly regulated and titratable in response to Dox, with the expected protein localization to ER-reticular structures (Fig. 1c and $\mathrm{d}$ and Supplementary Fig. 1B-D).

We then characterized BIK-induced apoptotic signaling. BIK expression stimulated subtle yet significant activation of caspases in the majority of MDA-MB-231 cells as measured by the caspase indicator CaspACE (Fig. 2a, and Supplementary Fig. 3). MCF-7 cells are deleted for caspase $-3^{26}$, so we evaluated caspase 7 and observed BIKinduced activation that was caspase dependent, as 


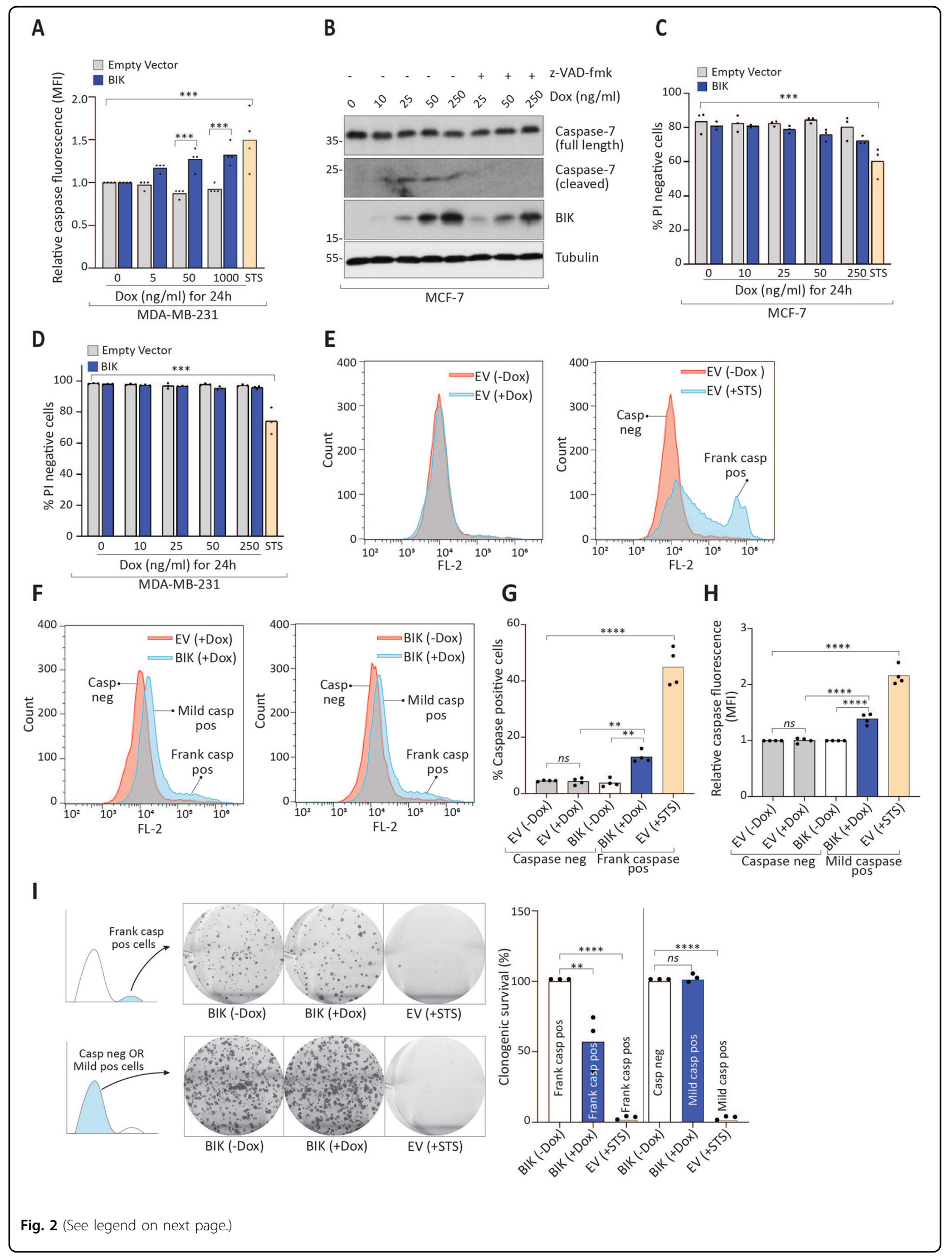


(see figure on previous page)

Fig. 2 BIK induces sublethal apoptosis with DNA damage. a Quantitation of relative mean fluorescence intensity after stimulating MDA-MB-231 Tet-on cells at the indicated doses of Dox for $24 \mathrm{~h}$ followed by staining with $10 \mu \mathrm{M}$ of CaspACE (FITC-VAD-FMK) and flow-cytometric analysis. Four independent experiments were performed and at least 10,000 cells (5000 for staurosporine) were acquired for all treatments. One-way ANOVA followed by Sidak's post-hoc test was performed to compute significance among groups. b Western blot analysis of MCF-7 Tet-on cells expressing BIK at the indicated Dox concentrations in the presence or absence of z-VAD-fmk $(10 \mu \mathrm{M})$ for $24 \mathrm{~h}$. $\mathbf{c}, \mathbf{d}$ MCF-7 and MDA-MB-231 Tet-on cells were, respectively, stimulated with indicated doses of Dox for $24 \mathrm{~h}$ followed by staining with propidium iodide and flow-cytometric analysis. At least 10,000 cells were acquired for three independent experiments. One-way ANOVA followed by Sidak's post-hoc test was performed to compute significance among groups. e, $\mathbf{f}$ Flow-cytometry profiles of MDA-MB-231 Tet-on cells stained with Cell Event Green caspase reporter. Cells were stimulated at the indicated doses of Dox for $24 \mathrm{~h}$ followed by staining with $5 \mu \mathrm{M}$ of Cell Event Green reporter followed by flow-cytometric analysis. Note the rightward shift of the histogram profiles of BIK-expressing cells. $2.5 \mu \mathrm{M}$ staurosporine was used as a positive control. $\mathbf{g}$ Bar graph depicting \% caspase-positive cells obtained by quantitation of $\mathbf{e}$, $\mathbf{f}$. Four independent experiments were performed and at least 10,000 cells were acquired for all treatments. Oneway ANOVA followed by Sidak's post-hoc test was performed to compute significance among groups. $\mathbf{h}$ Bar graph depicting the quantitation of relative mean fluorescence intensity for the main peak of the histograms shown in $\mathbf{e}$ and $\mathbf{f}$. Four independent data points were collected and for all treatments. One-way ANOVA followed by Sidak's post-hoc test was performed to compute significance among groups. i (Left) Representative images of clonogenic survival assay after sorting MDA-MB-231 cells displaying frank or mild caspase activation. Cells were treated with $250 \mathrm{ng} / \mathrm{ml}$ of Dox or STS as indicated for $24 \mathrm{~h}$ followed by staining with $5 \mu \mathrm{M}$ of Cell Event Green reporter followed by fluorescence-activated cell sorting. Thousands cells each were collected directly in cell-culture plates from the left or right side cell populations on the histogram by positioning sorting gates in the center of the respective peaks. Colonies were allowed to form for 8 days. Histogram cartoons on the extreme left indicate which part of the flowcytometry histogram was used to collect cells. (Right) Bar graph depicting \% clonogenic survival of frank or mild caspase-positive cells. Three independent experiments were performed. One-way ANOVA followed by Sidak's post-hoc test was performed to compute significance among groups.

expected for an executioner caspase (Fig. 2B). Additionally, BIK expression caused a significant loss of mitochondrial potential in $\sim 5 \%$ of MDA-MB-231 cells (Supplementary Fig. 2) relative to the untreated or empty vector controls, suggesting mitochondrial effects. Despite caspase activation, there was no significant cell death in either cell-line model as assessed by vital dye uptake for up to $48 \mathrm{~h}$ after BIK induction (Fig. 2c, d and Supplementary Fig. $4 \mathrm{~A}$ and $\mathrm{B})$.

Next, we interrogated the extent of BIK-induced caspase activation and its impact on the long-term survival of cells. We expressed BIK followed by staining with the active caspase reporter dye (Cell Event Green) to quantitate caspase-3/7 positive cells. Intriguingly, the entire population of BIK-expressing cells activated caspases, with $\sim 10 \%$ of cells showing $\sim 30$-fold frank caspase activation while the remaining $90 \%$ had mild but statistically significant 1.4-fold activation of caspases (Fig. 2e-h). Thus, BIK expression produced two distinct cell populations with either mild or frank levels of caspase activation. We separated these two populations by fluorescenceactivated cell sorting (FACS) and assessed cellular clonogenic potential with colony-formation assays. Of the frankly positive cell population from BIK-expressing cells, clonogenic potential was reduced by $\sim 50 \%$ (Fig. $2 \mathrm{i}$, top panel). This was in contrast to frankly caspase-positive cells from staurosporine treatment, which formed no colonies. Thus, cells could tolerate high levels of BIKinduced caspase activity, but not staurosporine-induced caspase activation. Intriguingly, cells with BIK-induced mild caspase activity showed robust clonogenic potential, while staurosporine-treated cells with similar mild caspase activation did not survive (Fig. 2i, bottom panel).
Therefore, despite BIK-mediated caspase activation, cells survived and formed colonies. To confirm this, we also assessed the proliferative capacity of cultured cells for up to 8 days with continued BIK induction and found that cells proliferated with similar kinetics as control cells (Supplementary Fig, 4C-G). Thus, BIK triggered caspase activation, although cells remained viable, maintained clonogenic potential, and ability to proliferate, demonstrating that BIK induced failed or sublethal apoptosis in the majority of cells.

Failed apoptosis stimulates nuclease-dependent DNA fragmentation leading to mutation accumulation and transformation ${ }^{10-12}$. We therefore investigated whether BIK induced DNA fragmentation. We measured phosphorylation of the DNA double-strand break (DSB) marker histone $\mathrm{H} 2 \mathrm{AX}-\mathrm{Ser} 139(\gamma \mathrm{H} 2 \mathrm{AX})$ in the total cell population as well as in cells with mild caspase activation as detected by Cell Event Green staining followed by FACS-based cell sorting (Fig. 3a). BIK expression increased $\gamma \mathrm{H} 2 \mathrm{AX}$ phosphorylation in the total cell population, which was inhibited by the pan-caspase inhibitor z-VAD-fmk (Fig. 3a, right side panel). Intriguingly, BIK-induced mild caspase activation also triggered caspase-dependent $\gamma \mathrm{H} 2 \mathrm{AX}$ phosphorylation (Fig. 3a, left side panel) although to a smaller extent. This observation combined with the colony-formation results (Fig. 2i) suggested that the majority of BIK-expressing cells exhibited caspase-dependent DNA damage and survived. Additionally, through siRNA mediated silencing we confirmed that DNA damage in BIK-expressing cells was specific to BIK (Fig. 3b) and increased in a BIK dosedependent manner (Fig. 3c). BIK resides at the endoplasmic reticulum where it stimulates $\mathrm{Ca}^{2+}$ release ${ }^{27,28}$. 


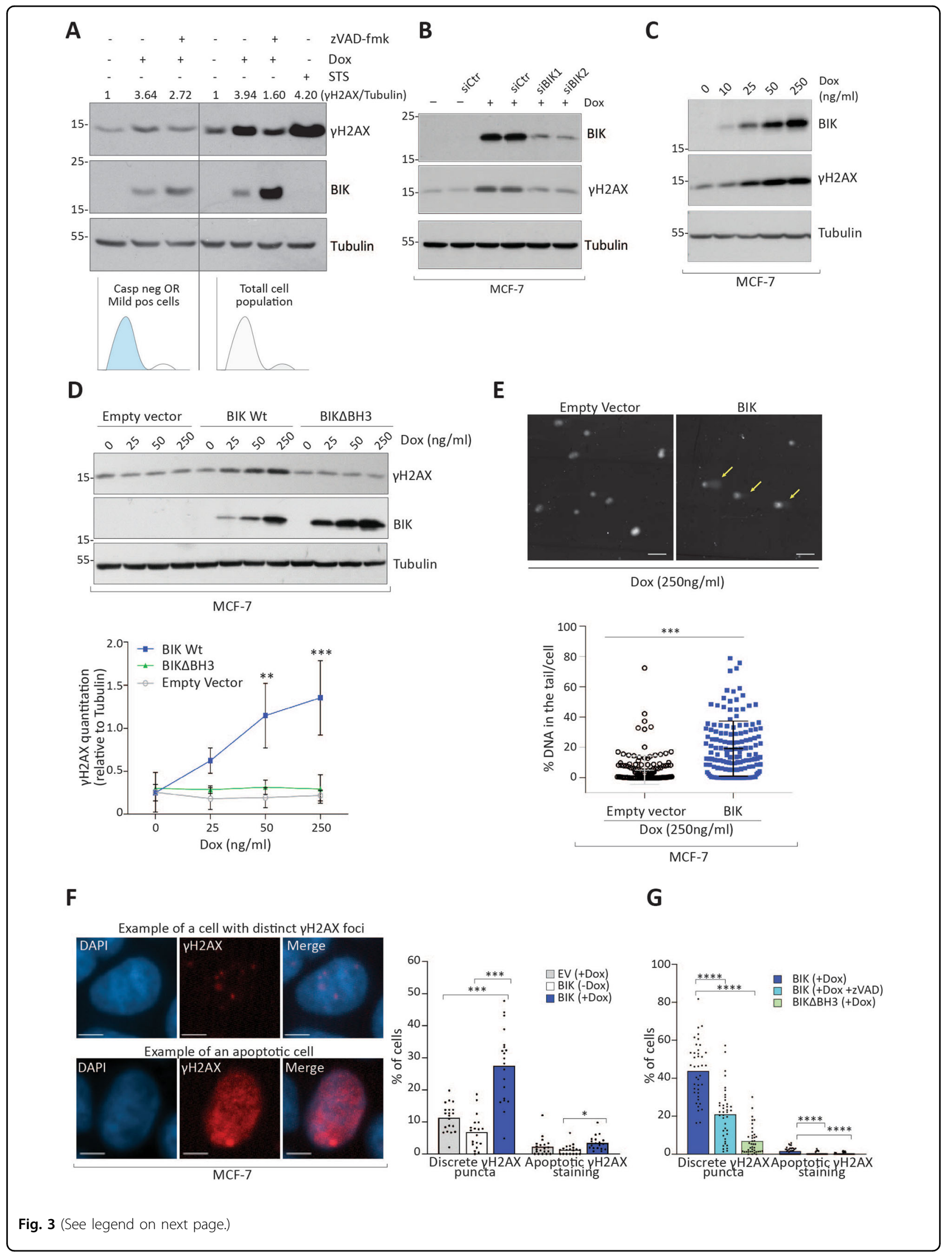




\begin{abstract}
(see figure on previous page)
Fig. 3 BIK induces discrete foci of DNA damage. a Western blot analysis after sorting MDA-MB-231 cells displaying mild caspase activation (left) or total cell population. Cells were treated with $250 \mathrm{ng} / \mathrm{ml}$ of Dox or STS $(2.5 \mu \mathrm{M})$ as indicated for $24 \mathrm{~h}$ followed by staining with $5 \mu \mathrm{M}$ of Cell Event Green reporter followed by fluorescence-activated cell sorting. To obtain cells with mild caspase activation, 100,000 cells were collected from the left side cell populations on the FACS histogram by positioning the sorting gate in the center of the peak. For total cell population analysis (right), cells grown and treated in cell-culture plates were directly collected by trypsinization. Floaters were collected in both cases. Cell lysates were prepared in RIPA buffer and $20 \mu \mathrm{g}$ total protein was resolved on a 12\% SDS-PAGE followed by western blotting with the indicated antibodies. Histogram cartoons at the bottom indicate which part of the flow-cytometry histogram was used to collect cells. $\mathbf{b}$ Western blot showing siRNA mediated knockdown of BIK expression reduces $\gamma \mathrm{H} 2 \mathrm{AX}$ formation. MCF-7 Tet-on cells were pretransfected with either scrambled or two BIK specific siRNAs, and $24 \mathrm{~h}$ later stimulated with $50 \mathrm{ng} / \mathrm{ml}$ Dox. c Western blot analysis of BIK expression and $\mathrm{YH} 2 \mathrm{AX}$ formation in MCF-7 Tet-on cells using indicated amounts of Dox. d Top: Western blot analysis of MCF-7 Tet-on cells expressing either Empty vector, Wt BIK or BIK $\triangle B H 3$ at the indicated Dox induction for $24 \mathrm{~h}$. Bottom: Densitometric quantitation of three independent western blots was performed using ImageJ. Error bars represent SD. One-way ANOVA followed by Tukey's post-hoc test was performed to compute significance among groups. e Top: Representative images of comets formed by Empty vector or BIK-expressing MCF-7 cells at the indicated Dox stimulation for $24 \mathrm{~h}$. Bottom: \% DNA in the comet tail per nuclei was quantitated using CaspLab comet analysis program. A total of 150 nuclei from three independent experiments were analyzed. An unpaired two-tailed t-test was performed to determine the $\mathrm{p}$-value. Scale bar $100 \mu \mathrm{m}$. $\mathbf{f}$ Left: Representative images of $\mathrm{\gamma H} 2 \mathrm{AX}$ immunofluorescence analysis of BIK-expressing cells. Right: Quantitation of cells with discrete $\mathrm{yH} 2 \mathrm{AX}$ puncta representing DNA damage or diffuse staining representing apoptotic morphology. $n=19-20$ frames of images with 2569 nuclei for BIK (-Dox), 1652 for BIK (+Dox) and 1693 for Empty vector (+Dox) were analyzed from two biological replicates. One-way ANOVA followed by Sidak's post-hoc test was performed to compute significance among groups. Scale bar $5 \mu$ m. $\mathbf{g}$ Quantitation of cells with discrete $\mathrm{YH} 2 \mathrm{AX}$ puncta representing DNA damage or diffuse staining representing apoptotic morphology. $n=40$ frames of images with 2946 nuclei for BIK (+Dox), 3484 for BIK (+Dox +z-VAD-fmk), and 3804 for BIK $\triangle B H 3$ (+Dox) were analyzed from four biological replicates. One-way ANOVA followed by Sidak's post-hoc test was performed to compute significance among groups.
\end{abstract}

BIK-stimulated mitochondrial calcium overload may result in reactive oxygen species (ROS) production, which could also generate DSBs. To estimate the contribution of ROS-induced DNA damage in BIK-expressing cells, we first measured ROS levels in individual cells. BIK expression did not increase levels of ROS (Supplementary Fig. 5A), and BIK-induced $\gamma \mathrm{H} 2 \mathrm{AX}$ was unaffected by treatment with the ROS scavenger $\mathrm{N}$-acetylcysteine (NAC) (Supplementary Fig. 5B), indicating that ROS was not an effector of BIK-induced DNA damage. Instead, DNA damage was dependent on the BIK-BH3 domain indicative of the classic mitochondrial apoptotic pathway (Fig. 3d). In support of this, DNA damage diminished in the presence of the pan-caspase inhibitor z-VAD-fmk (Supplementary Fig. 5B). This caspase-dependency suggested that Caspase Activated DNase (CAD) contributed to DNA damage and indeed its silencing reduced $\gamma \mathrm{H} 2 \mathrm{AX}$ levels (Supplementary Fig. 5C). Finally, to confirm that $\gamma \mathrm{H} 2 \mathrm{AX}$ positivity was indeed due to DNA damage, we performed single-cell electrophoresis assays (comet assay) and observed significantly increased levels of genomic DNA cleavage in BIK-expressing cells (Fig. 3e and Supplementary Fig. 5D). Together these data demonstrated that BIK stimulated the mitochondrial apoptotic program that activated caspases and CAD to induce DNA DSBs.

Next, we tested whether the $\gamma \mathrm{H} 2 \mathrm{AX}$ positivity was a function of large scale apoptotic DNA cleavage ${ }^{29}$ or discrete DSBs per cells. We analyzed the subcellular morphology of $\gamma \mathrm{H} 2 \mathrm{AX}$-staining and detected less than $5 \%$ of the cells with bright, diffuse $\gamma \mathrm{H} 2 \mathrm{AX}$ nuclear staining characteristic of advanced apoptosis (Fig. 3f), confirming that BIK induced minimal cell death (Fig. 2c). Instead, nearly one-third of BIK-expressing cells showed $\gamma \mathrm{H} 2 \mathrm{AX}$ staining in discrete puncta indicative of limited DSB (Fig. 3f). BIK-mediated discrete $\gamma \mathrm{H} 2 \mathrm{AX}$ positivity was dependent on caspase activity, as treatment with the caspase inhibitor z-VAD-fmk or expression of an apoptosis-defective $\mathrm{BIK} \triangle \mathrm{BH} 3$ mutant $^{30}$ significantly reduced the numbers of $\gamma \mathrm{H} 2 \mathrm{AX}$ puncta (Fig. 3g). Importantly, despite the generation of DNA damage, cells continued to double (Supplementary Fig. 4C-G), suggesting that DNA DSBs were resolved sufficiently to support cell proliferation and expansion.

\section{BIK induces heritable changes to cell progeny}

To examine the consequences of BIK-induced sublethal apoptosis over multiple cell generations, we plated MCF-7 and MDA-MB-231 cells at single-cell density and characterized resulting cell colonies in response to continual BIK expression. The majority of BIK-expressing cells generated colonies with reduced efficiency, indicating defective clonogenic potential (Fig. 4a and Supplementary Fig. 6A). Additionally, BIK-expressing colonies displayed "frail" morphology with significantly reduced colony area (Fig. 4b, and Supplementary Fig. 6B) and density (Fig. 4c and Supplementary Fig. 6C), highlighting differential growth phenotypes. Thus, BIK expression altered growth properties over multiple cell generations. One mechanism whereby sublethal apoptosis induces phenotypic changes is via genomic instability and mutation accumulation that is inherited by cell progeny ${ }^{9}$. To determine whether BIKinduced phenotypic changes were heritable, we expressed BIK continuously for 10 passages, then removed Dox and maintained cells in the absence of Dox/BIK (Fig. 5a). BIK 


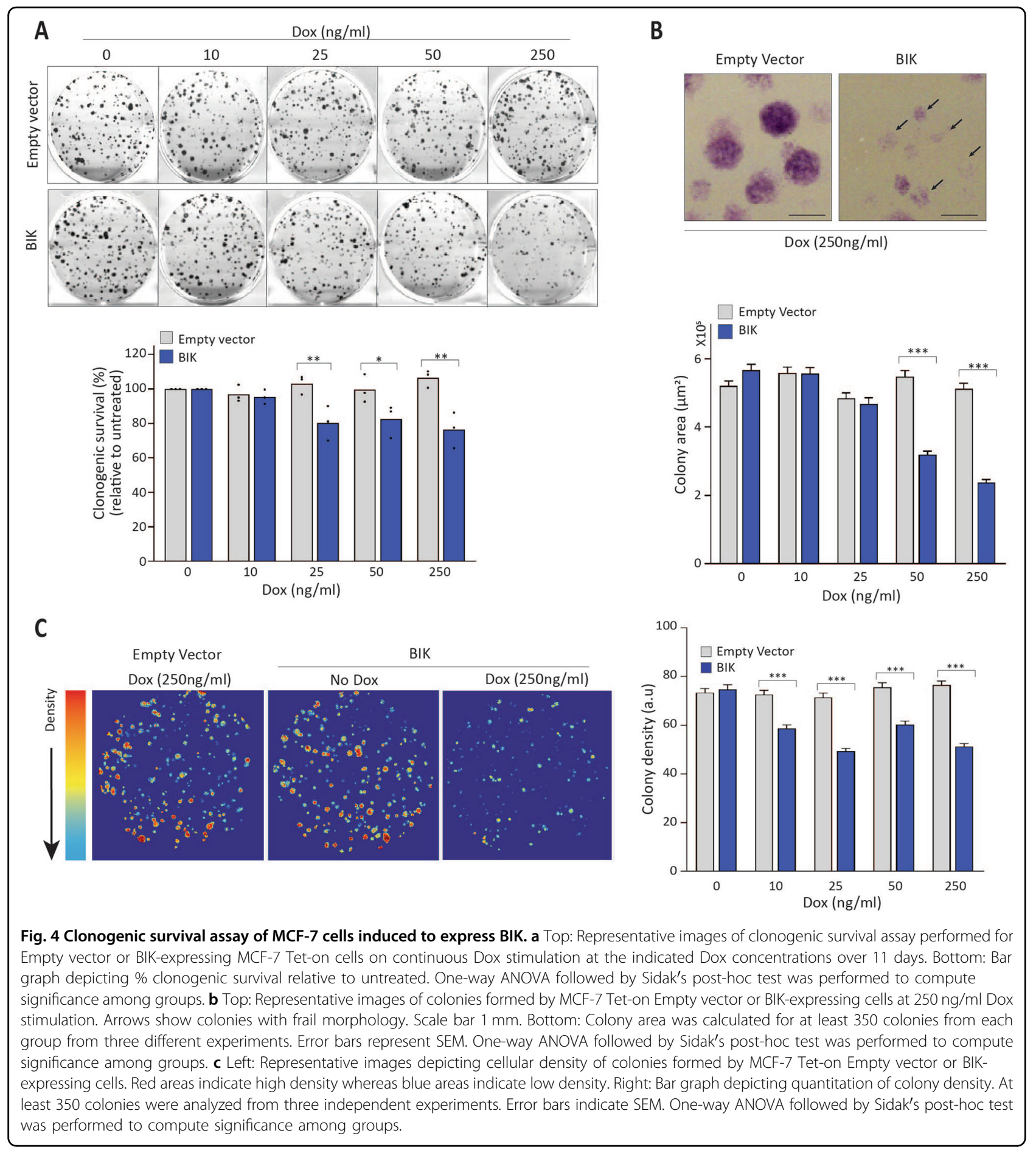

protein expression and subsequent DNA damage persisted for the duration of Dox treatment (Fig. 5b; BIK ON) and became undetectable after the removal of Dox (Fig. 5b; BIK OFF and Supplementary Fig. 7A). This indicated persistent DNA damage in cells grown in the presence of BIK that was diminished in daughter cells following termination of BIK expression. We refer to the progeny of these long-term Dox-treated cells with the annotation "LTC" (for Long Term Culture) and Dox-concentration during treatment. For example, BIK-LTC-250 signifies that BIK expression was induced for 10 passages in $250 \mathrm{ng} / \mathrm{mL}$ Dox after which it was maintained in the absence of Dox. These cells were cultured for at least five passages in the absence of Dox/BIK to assess stable 


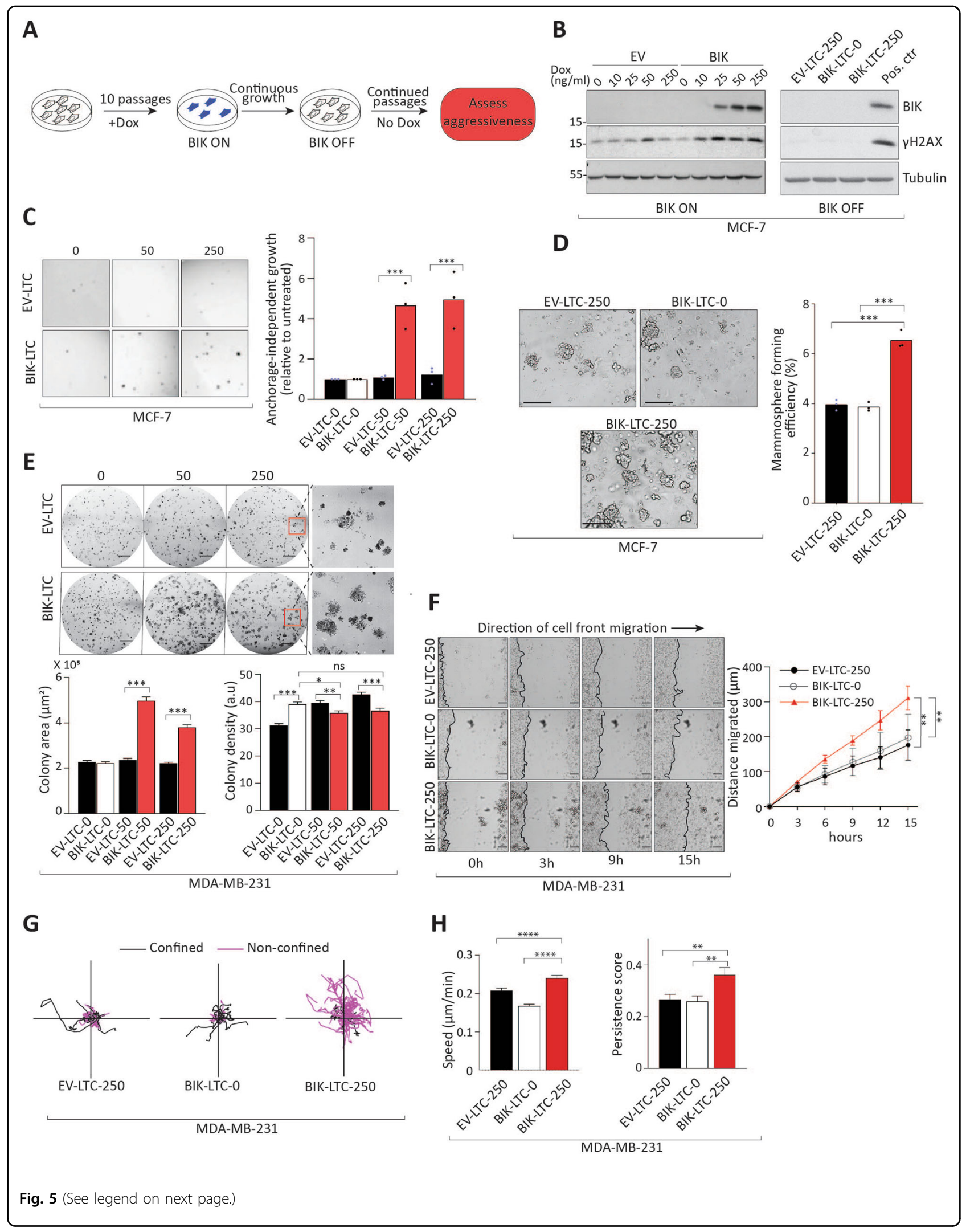


(see figure on previous page)

Fig. 5 Long-term BIK expression promotes aggressive cell phenotypes. a Experimental scheme depicting the generation of "LTC" cells. $\mathbf{b}$ Left: Western blot analysis performed for MCF-7 Tet-on cells after 10 passages in Dox showing the persistence of BIK expression and DNA damage. Right: Western blot analysis showing BIK expression turned off and DNA damage resolved after Dox withdrawal. Cell lysates made from cells expressing BIK were used as a positive control for anti-BIK and - $\mathrm{yH} 2 \mathrm{AX}$ antibodies. $\mathbf{c}$ Left: Representative images depicting the anchorage-independent growth of MCF-7 LTC cell lines. Right: Quantitation of the fold changes in the number of soft-agar colonies relative to control. Three independent experiments were performed. One-way ANOVA followed by Sidak's post-hoc test was performed to compute significance among groups. $\mathbf{d}$ Left: Representative images from mammosphere formation assay performed with MCF-7 LTC cell lines. Mammosphere-forming efficiency (MFE) was calculated after 12 days in culture. Scale bar $250 \mu \mathrm{m}$. Right: Bar graph depicting quantitation of the MFE from three independent experiments. One-way ANOVA followed by Sidak's post-hoc test was performed to compute significance among groups. e Top: Representative images from colony-formation assay performed for MDA-MB-231 LTC cells. Scale bar $5 \mathrm{~mm}$. The satellite images show a magnified view of the colonies. Bottom Left: Colony area was calculated for at least 350 colonies from each group from three different experiments. Error bars represent SEM. One-way ANOVA followed by Sidak's post-hoc test was performed to compute significance among groups. Bottom Right: Colony density was calculated for at least 350 colonies from each group from three different experiments. Error bars represent SEM. One-way ANOVA followed by Sidak's post-hoc test was performed to compute significance among groups. $\mathbf{f}$ Left: Representative images at the indicated time-points from the collective cell migration assay performed for MDA-MB-231 LTC cells. Right: Quantitation of the movement of the cell-front over $15 \mathrm{~h}$. A total of nine positions from three independent experiments were analyzed for each group. Error bars represent SD. Linear regression analysis was performed to calculate differences between groups. Scale bar $100 \mu \mathrm{m}$. $\mathbf{g}$ Rose plots depicting the spread of cell movements of the MDA-MB-231 LTC cells. $\mathbf{h}$ Speed (left) and persistence (right) for MDA-MB-231 LTC cells were calculated by taking the average speed of cells over $24 \mathrm{~h}$. At least 57 tracks were analyzed from three independent experiments. Error bars represent SEM. One-way ANOVA followed by Sidak's post-hoc test was performed to compute significance among groups.

changes induced by this "transient" BIK expression. We first tested whether these cells survived 10 passages with high levels of BIK due to a compensatory elevation of antiapoptotic proteins (Supplementary Fig. 8A). BCL-2, BCL-XL, or MCL-1 protein levels were not elevated, and GRP78, which is a specific inhibitor of $\mathrm{BIK}^{31,32}$ was also not elevated in the BIK-LTC cell lines. This observation was consistent with patient tumor samples whereby antiapoptotic gene expression and BIK gene expression did not correlate ${ }^{15}$.

We next assayed whether long-term BIK expression induced aggressive growth characteristics. We interrogated anchorage-independent growth and stem-like properties that are associated with therapeutic resistance in breast and colon cancer models ${ }^{33,34}$. When prevented from attaching to a solid substratum, MCF-7 BIK-LTC250 cells formed $\sim 5$ times more (Fig. 5 c) and MDA-MD231 BIK-LTC-250 cells formed $\sim 3.5$ times more anchorage-independent colonies than their controls (Supplementary Fig. 10A), indicative of an aggressive phenotype. Mammosphere-forming assays that involve cell culture in low-attachment conditions in the absence of serum assess the stem-like properties of cells ${ }^{35,36}$. BIKLTC-250 cell lines derived from both MCF-7 and MDAMB-231 cells had $\sim 1.7$ times increased numbers of mammosphere colonies than their control EV-LTC-250 or BIK-LTC-0 cell lines, indicating that BIK-treatment increased the proportion of cancer stem-like cells (Fig. 5d and Supplementary Fig. 10B). We measured the area of these mammospheres, which is associated with tumorinitiating potential ${ }^{37}$. Interestingly, the mammospheres formed by MCF-7 BIK-LTC-250 had increased area (Supplementary Fig. 8B), whereas MDA-MB-231 BIK-LTC-250 mammosphere area was unchanged
(Supplementary Fig. 10B). Departure from the spherical mammosphere morphology is associated with aggressive phenotypes $^{38-41}$. The mammospheres formed by both MCF-7 and MDA-MB-231 BIK-LTC-250 cells were more irregularly shaped and less spherical compared to their EV-LTC-250 cells as indicated by the isoperimetric quotient that is a measure of circularity (Supplementary Figs. 8B. 10B). Thus, early but nonpersistent BIK expression generated cells with increased anchorage-independent growth and with increased stem-like characteristics indicating that BIK imparted heritable changes in progeny (Supplementary Table 1).

We further characterized if BIK expression altered clonogenic potential in standard 2-dimensional culture conditions. Indeed, MCF-7 BIK-LTC-250 cells had significantly increased colony numbers with unchanged colony area and cell density (Supplementary Fig. 8C and D), consistent with an increased proportion of stem-like cells. Furthermore, we interrogated if BIK-induced aggressiveness required the apoptotic $\mathrm{BH} 3$ domain and was caspase-dependent. We therefore generated LTC lines expressing the BIK $\triangle \mathrm{BH} 3$ mutant or cultured wildtype BIK-expressing cells in the presence of $\mathrm{z}$-VAD-fmk for 10 passages (Supplementary Fig. 7B, left side panel, BIK ON). BIK and BIK $\triangle B H 3$ expression persisted through 10 passages, and as expected, the amount of $\gamma \mathrm{H} 2 \mathrm{AX}$ remained lower than the basal $\gamma \mathrm{H} 2 \mathrm{AX}$ observed after BIK expression was turned off (Supplementary Fig. $7 \mathrm{~B}$, left side panel, BIK OFF). We then assessed the clonogenic potential of the LTC cell lines BIK $\triangle B H 3-L T C-$ 250 and BIK-LTC-250-z-VAD relative to BIK-LTC-0 and BIK-LTC-250 cell lines. The clonogenic potentials of BIK $\triangle B H 3-L T C-250$ or BIK-LTC-250-z-VAD cell lines were not significantly different compared to the negative 
control BIK-LTC-0 cell line (Supplementary Fig. 8E). In contrast, BIK-LTC-250 cells formed increased numbers of colonies compared to control BIK-LTC-0, BIK $\Delta \mathrm{BH} 3-$ LTC-250, and BIK-LTC-250-z-VAD cell lines (Supplementary Fig. 8E). Combined with our previous results, these observations demonstrated that the $\mathrm{BH} 3$ domain of $\mathrm{BIK}$ and caspase activation are required for BIK-initiated sublethal apoptosis, increased DNA damage and subsequent cancer aggression. While MDA-MB-231 BIKLTC-250 clonogenic survival was not different than control EV-LTC-250 or BIK-LTC-0 cell lines (Fig. 5e and Supplementary Fig. 10C), BIK expression did induce significant differences in colony morphology. MDA-MB-231 BIK-LTC-250 cells formed colonies with a $\sim 2$-fold increase in the colony area and $\sim 1.2$-fold reduction in the colony density (Fig. 5e), suggestive of decreased cell adhesion and increased migration. In order to assess the migratory properties of the LTC cells, we tested collective and individual cell migration by wound healing and single-cell tracking assays, respectively. Collective cell migration of the MDA-MB-231 BIK-LTC-250 cells was significantly elevated (Fig. 5f). Furthermore, we investigated if this increase in the migratory properties was dependent on caspase activation. We cultured BIKexpressing MDA-MB-231 cells in the presence of pancaspase inhibitor z-VAD-fmk for 10 passages (Supplementary Fig. 7B, right side panel, BIK ON). While BIK expression persisted through 10 passages, the amount of $\gamma \mathrm{H} 2 \mathrm{AX}$ remained similar to basal $\gamma \mathrm{H} 2 \mathrm{AX}$ observed in this cell line after BIK expression was turned off (Supplementary Fig. 7B, right side panel, BIK OFF), confirming that $\mathrm{z}$-VAD-fmk had effectively blocked BIK-mediated caspase-dependent $\gamma \mathrm{H} 2 \mathrm{AX}$ production in this cell line. Assessment of collective migration revealed that BIKLTC-250 cells migrated faster than BIK-LTC-0 and BIKLTC-250-z-VAD cells (Supplementary Fig. 10D), indicating that evolution of increased cell motility required BIK and caspases. Furthermore, when analyzed at the single-cell level, MDA-MB-231 BIK-LTC-250 cells migrated with higher speed and persistence (the ability of cells to maintain a specific direction of motion) (Fig. $5 \mathrm{~g}$ and h). The MCF-7 BIK-LTC-250 cell line did not show increased collective or single-cell migration compared to control cells (Supplementary Fig. 9A and B), consistent with an unaltered colony morphology. Thus, BIK expression increased the migratory properties of MDA-MB-231 but not MCF-7 progeny, indicating that BIK altered molecular pathways in a cell-line-specific manner, which facilitated the evolution of differential cell phenotypes.

Taken together, these data are consistent with the proposition that BIK can facilitate heritable changes to pathways that increase the proportion of cancer stem-like cells, anchorage-independent growth, cell migration as well as colony-formation ability in the surviving cell population.

\section{High BIK mRNA and protein levels predict unfavorable outcomes in ER-positive breast cancer patients}

To understand the clinical significance of high $B I K$ levels in relation to the survival outcomes of breast cancer patients, we examined $B I K$ mRNA levels in five publically available datasets ${ }^{42-48}$. Breast cancers can be broadly divided into hormone receptor- and HER2-positive (nonTNBC) or negative (TNBC) categories. Non-TNBCs are either treated with antiestrogens or Herceptin therapy whereas the TNBCs have no targeted therapy and are treated with a combination of chemotherapeutic agents $^{48,49}$. As well, non-TNBC patients have better survival outcomes than the TNBC patients due to the differences in the biology and treatment modalities of the disease $^{48}$. We decided to investigate BIK transcript levels in these two groups using publically available gene microarray dataset ${ }^{45-47}$. Intriguingly, we found that nonTNBCs had 3.2-fold increased levels of BIK mRNA relative to the TNBCs (Fig. 6a), suggesting relevance to hormonal signaling. Therefore, we next interrogated the prognostic value of $B I K$ mRNA levels in ER-positive patients, which represent $>80 \%$ of all non-TNBC patients. We performed ROC analysis with disease-free survival as a classifier to determine the optimum score cut point. Intriguingly, by utilizing two independent patient cohorts (combined $n=345)^{42,43}$, we discovered that patients with high levels of $B I K$ mRNA had an average of 3.7-fold increased risk $(p<0.0005)$ of disease relapse (Fig. $6 \mathrm{~b}$ and Supplementary Fig. 11A). On the contrary, we found that $B I K$ had no predictive value for TNBC patients (Fig. $6 \mathrm{c}$ and Supplementary Fig. 11B and C; $p>0.05$ ) by analyzing three independent TNBC patient cohorts (combined $n=$ $472)^{44,45,50}$.

In order to interrogate these results at the level of BIK protein, we analyzed whether BIK protein levels predicted relapse in ER-positive breast cancer patients differently than in ER-negative patients $(n=152)$ (Fig. 6D). We determined BIK protein levels by anti-BIK immunohistochemistry followed by ROC analysis to determine the score cut point as described previously ${ }^{15}$. Strikingly, within the ER-positive subtype $(n=116)$, BIK-high patients were 8.4 times more likely to relapse $(p=0.001$, $95 \% \mathrm{CI}=2.25-32.0)$ and were 8.1 times more likely to die from the disease $(p=0.025,95 \% \mathrm{CI}=1.26-52.5)$, relative to BIK-low patients (Fig. 6d and e). Intriguingly, 99\% of patients with low levels of BIK protein were alive after 5 years. On the other hand, BIK levels did not predict the disease-free $(p=0.73,95 \% \mathrm{CI}=0.28-6.07)$ or overall survival $(p=0.48,95 \% \mathrm{CI}=0.33-9.33)$ outcomes of the ER-negative patients (Fig. 6d and e). 


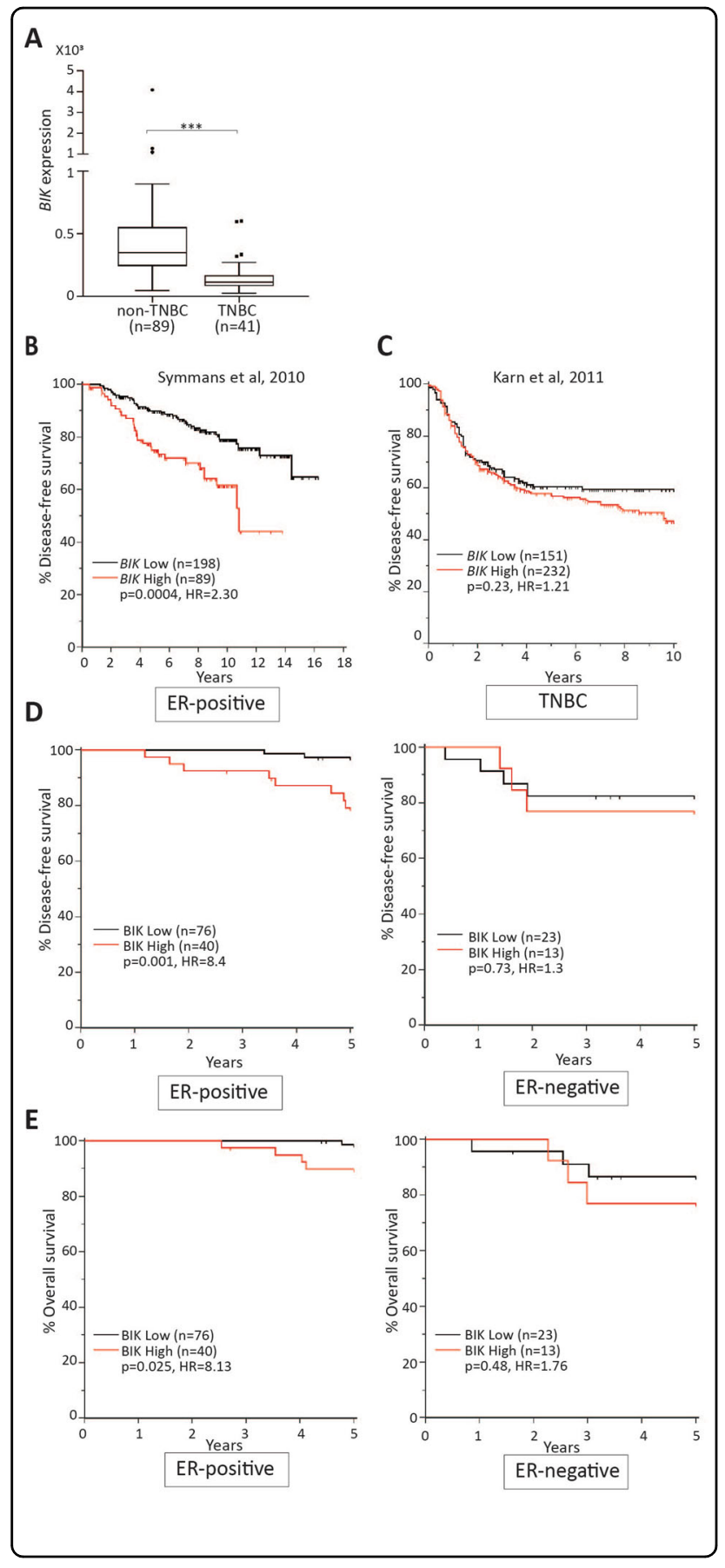

Thus, BIK predicted recurrence and mortality in ERpositive breast cancer cohorts, suggesting that BIKmediated sublethal apoptosis may contribute to clinical tumor evolution specifically in this subset of breast cancers.

\section{Discussion}

Cancer treatment aims to minimize residual disease that causes relapse. However, the fate of surviving cells that
Fig. 6 High BIK mRNA and protein levels predict poor survival of ER-positive breast cancer patients in multiple datasets. a A Tukey box and whisker plot depicting BIK gene expression values in nonTNBC and TNBC patients obtained from the publicly available dataset GSE65194. The horizontal line inside the box represents the median. Student's two-tailed $t$-test was performed to determine statistical significance between the two groups. b Kaplan-Meier survival curves depicting disease-free survival outcomes of a total of 287 ER-positive patients stratified into BIK-high and -low groups based on BIK mRNA levels in tumors. The hazard ratio (HR) value of greater than 1.0 estimates the predicted risk of poor prognosis. P-value was calculated using the log-rank test. c Kaplan-Meier survival curves depicting disease-free survival outcomes of a total of 383 TNBC patients stratified into BIK-high and -low groups based on BIK mRNA levels in tumors. d, e Kaplan-Meier survival curves depicting five-year diseasefree or overall survival outcomes of a total 152 of patients stratified in ER-positive antiestrogen treated vs. ER-negative groups. Survival outcomes were calculated based on BIK protein levels in tumor cores. The hazard ratio (HR) value of greater than 1.0 estimates the predicted risk of poor prognosis. P-value was calculated using the log-rank test.

have escaped cell death after the apoptotic challenge remains largely unknown. In line with this, BIK is well documented to potently induce cell death ${ }^{24,27,31,51-57}$, yet in those studies, $27-65 \%$ of cells escaped death and whether these surviving cells developed aggressive phenotypes was unknown. Our study in combination with others $^{6,10,11,13,58-61}$ supports the notion that survivors of apoptosis can actively gain aggressive properties through sublethal caspase signaling in the absence of antiapoptotic upregulation (Fig. 7). In support of this, genetic deletions of proapoptotic molecules, such as BID, PUMA, and caspase-3/7 prevent oncogenesis ${ }^{59-61}$, and high levels of antiapoptotic BCL-2 are associated with favorable patient outcomes in breast, colorectal, and lung cancers ${ }^{6,7,58,62}$. In this context, our study provides novel insight into failed apoptosis triggered by the stress/estrogen deprivationinduced protein BIK and links this adverse association with clinical patient outcome (Fig. 7).

The fate of cells that have been exposed to the longterm apoptotic challenge was not known, and this is highly relevant as breast cancer patients are typically treated with adjuvant hormonal therapy for 2-10 years. Under culture conditions, the majority of BIK-expressing cells not only survive but also proliferate and can form colonies from single cells. At present, the mechanism of cell survival is not clear. Recent studies have identified a process called anastasis wherein cells transiently exposed to apoptotic stimuli show typical morphological features of apoptosis but upon recovery in fresh medium, reattach, and proliferate ${ }^{63,64}$. These surviving cells display aggressive behaviors such as increased motility by upregulating drivers of epithelial to mesenchymal transition (EMT) such as Snail. Thus BIK may cause apoptotic activation followed by recovery in some cells, creating an anastasis- 


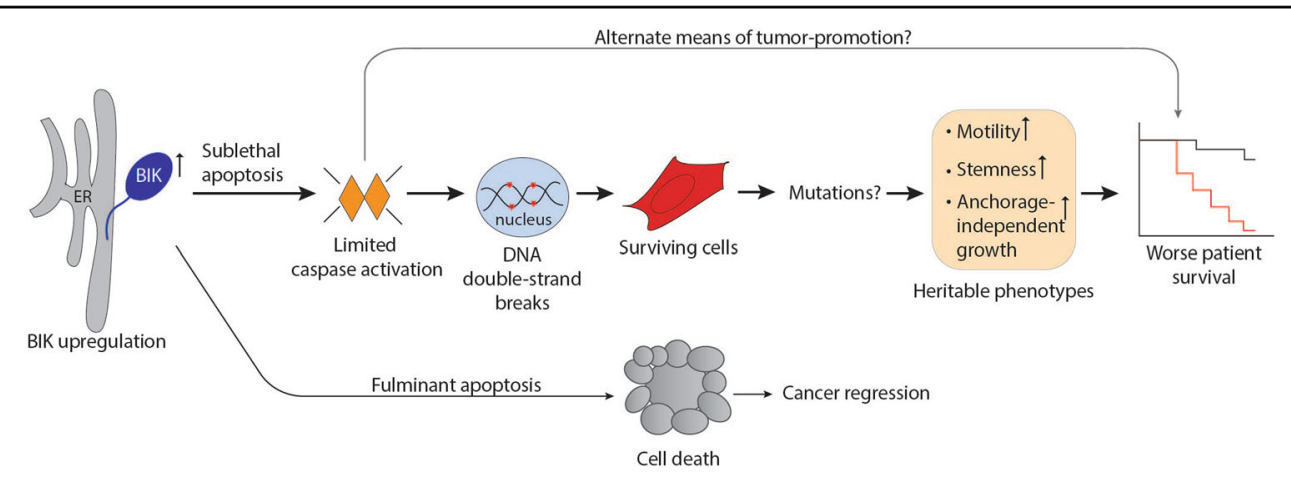

Fig. 7 BIK upregulation causes sublethal apoptosis and cancer aggression. Cartoon illustrating the underlying mechanism of tumor-promotion by BIK. ER-localized BIK signals sublethal apoptotic activation in cells leading to limited caspase activation. Activated apoptotic nucleases such as CAD cause DNA double-strand breaks and possible mutations in the surviving cells. These mutations may lead to aggressive cancer phenotypes that are heritable in nature. This mutation-driven tumor evolution combined with other caspase-dependent protumorigenic mechanisms may determine the poor patient prognosis of BIK-high patients.

like environment. An interplay between failed apoptosis and anastasis could partly explain the survival of BIKexpressing cells and their acquisition of increased motility after long-term culture. Another possible explanation for the survival of long-term BIK-expressing cells is that BIK stimulates both mild and frank activation of caspases wherein frank caspase activation leads to death of a portion of cell population that is sensitive to BIK-mediated apoptosis. A possibility that this may lead to the natural selection of aggressive-death-resistant cells can not be ruled out at this time. However, given that the majority of BIK-expressing cells show mild caspase activation and limited DNA damage, the ability of these cells to engage cell survival and repair pathways is a likely scenario.

Mutations and genomic instability have a major role in determining cancer heterogeneity. The aggressive phenotypes of BIK-LTC cell lines could be attributed to failed apoptosis-mediated mutagenesis. Caspase and apoptotic nuclease activation (CAD and EndoG) generate mutations and cause carcinogenesis in cell-based models ${ }^{9,12,65}$, although the relevance of these observations in the context of clinical disease was unknown. Interestingly, exome sequencing of 559 ER-positive tumors revealed low- and high mutational load (HML) groups wherein HML tumors were associated with poor prognosis $(\mathrm{HR}=$ $2.02)^{66}$. Considering our results, it would be interesting to determine if the HML tumors have a significantly elevated BIK protein. While mutagenesis driven cancer evolution is a likely scenario for heritable phenotypes that we have observed in vitro, alternative caspase-dependent mechanisms, such as cancer stem-cell enrichment and immune silencing through prostaglandin E2 (PGE2) signaling ${ }^{67,68}$, the competitive outgrowth of treatmentresistant clones ${ }^{69}$, as well as aberrant signaling between apoptotic cells and tumor-associated macrophages that in turn creates a premetastatic niche and facilitates angiogenesis ${ }^{9,70,71}$ may also contribute to cancer promotion in vivo (Fig. 7). Another important consideration is that while our observations support the tumor-promoting role of BIK in cell-based models and associate high BIK levels with poor patient prognosis, a direct causal relationship between BIK elevation, failed apoptosis, and tumor aggression in patient tumors is yet to be established. Further investigations will likely reveal the underlying biology in driving tumor evolution in vivo.

We identified that high levels of BIK are prognostic for ER-positive breast cancer but not for TNBC. Notably, BIK mRNA levels are significantly higher in hormonallydriven cancers compared to TNBCs, suggesting a minimum threshold of BIK is required to affect clinical outcomes. We speculate that ER-positive tumors have elevated BIK in response to local deprivation of estrogen, or diminished estrogen signaling, which is known to increase $B I K$ mRNA levels ${ }^{16,18}$. Furthermore, ER-positive breast cancer is treated with antiestrogen therapy known to stimulate BIK expression ${ }^{16,72}$. Thus, estrogendependent regulation of BIK may trigger sufficient sublethal apoptosis to impact patient outcomes only in the ER-positive subtype. BIK mRNA is significantly lower in TNBCs possibly due to the estrogen-independent nature of this subtype. Nevertheless, as seen with our study, ectopic BIK expression in the TNBC cell-line MDA-MB231 can cause sublethal apoptosis-driven cancer aggression. This observation is crucial given the fact that other tumor-associated stressors, such as hypoxia, DNA damage, and cytokines, can also trigger BIK expression ${ }^{19}$, which may contribute to sublethal apoptosis and tumor evolution in TNBCs as well. This is consistent with our observation that BIK-high TNBC patients show a trend of poor prognosis in three of the four patient cohorts. Thus, irrespective of the nature of the stress, BIK upregulation has the potential to drive tumor aggression in breast 
cancers. Altogether, our study provides a novel link between weak apoptotic induction and its potential to promote tumor evolution in BIK-high breast cancers.

\section{Materials and methods}

Lysate preparation from primary flash-frozen tumors

Patient tissue was collected under research ethics board approval (HREB Biomedical, Pro00030345). Primary breast tumors harvested during surgery were flash-frozen and stored at $-80^{\circ} \mathrm{C}$ until further processing. Tumor tissues were thawed on ice and ground using a Dounce homogenizer in RIPA buffer complete with protease and phosphatase inhibitors. Samples were then spun at maximum speed at $4{ }^{\circ} \mathrm{C}$. The supernatant was obtained and stored at $-80^{\circ} \mathrm{C}$. Total protein was quantitated using the BCA protein quantitation kit (Thermo Scientific, USA). $25 \mu \mathrm{g}$ of total protein was loaded for western blotting.

\section{Generation of Dox-inducible cell lines}

Dox-inducible MCF-7 Tet-On cell line was generated by transfecting MCF-7 cells with pTet-On vector (631018, Clontech, USA) followed by selection with $100 \mu \mathrm{g} / \mathrm{ml}$ G418 (Invitrogen, USA). A single clone was picked, and Tet repressor expression was confirmed using western blot for further experiments. MDA-MB-231 Tet-On cell line was a gift from Dr. Judith Hugh. Dox-inducible BIKexpressing cell lines were produced by cloning of Wt Bik or Bik $\triangle \mathrm{BH} 3 \mathrm{cDNAs}$ into pRetroX-Tight-Pur vector (Clontech, USA) between BamH I and EcoR I restriction sites. Replication-deficient retroviral particles were generated following the manufacturer's instructions and were used to transduce MCF-7 or MDA-MB-231 cells to generate stable cell lines (632104, Clontech, USA). Briefly, GP2-293 cells were transiently transfected with pRetroXTight-pur-Bik and pAmpho plasmids using Lipofectamine 2000 to produce retroviral particles. The supernatant containing viral particles was harvested at 24,48 , and $72 \mathrm{~h}$ intervals and MCF-7 or MDA-MB-231 Tet-On cells were transduced with those particles at 24,48 , and $72 \mathrm{~h}$ intervals (particles were not pooled) according to the manufacturer's protocol. Twenty-four hour after transduction, the medium was changed to selection medium containing $1 \mu \mathrm{g} / \mathrm{ml}$ Puromycin (Sigma, USA) and $100 \mu \mathrm{g} / \mathrm{ml} \mathrm{G418} \mathrm{for}$ 7 days to eliminate untransduced cells. Stable colonies formed by selected cells were pooled and expanded. Doxtitration to test dose-dependent increase in BIK protein levels was assessed by western blot and immunofluorescence. All cell manipulations up to this point were performed in Tet-free serum (Clontech, USA) and then switched to regular serum (Sigma, USA) after confirmation of lack of leaky BIK expression by western blots. For subsequent experiments, MCF-7 Tet-On BIK and MDAMB-231 Tet-On BIK cell lines were grown in RPMI +
$10 \%$ FCS medium after confirming the absence of any leaky expression.

\section{Western blotting}

Cell lysates were prepared in RIPA buffer $(50 \mathrm{mM}$ Tris$\mathrm{Cl}, 150 \mathrm{mM} \mathrm{NaCl}, 0.1 \%$ SDS, $1 \%$ NP-40, 0.5\% deoxycholate, and $1 \mathrm{mM}$ EDTA, pH 7.5) supplemented with protease- (11873580001, Roche, USA) and phosphatase inhibitors (04906837001, Roche, USA) and protein concentration was determined using BCA protein assay kit (Thermo Scientific, USA). Twenty microgram of total protein was resolved on 12\% SDS-PAGE and blotted on nitrocellulose membranes Amersham $^{\mathrm{TM}}$ Protran $^{\mathrm{TM}}$ Premium $0.2 \mu \mathrm{m} \mathrm{NC)} \mathrm{followed} \mathrm{by} \mathrm{probing} \mathrm{with} \mathrm{the} \mathrm{indi-}$ cated antibodies (Supplementary Table 3) overnight at $4{ }^{\circ} \mathrm{C}$. Next day, HRP-conjugated secondary antibodies (1:5000) (Santa Cruz Biotechnology, BioRad, and Cell signaling technologies, USA) were used followed by signal detection using ECL reagent (Amersham ${ }^{\mathrm{TM}}$, UK) and Xray film (FUJIFILM, Japan). Brightness and contrast adjustments on the images were evenly applied for better visual presentation. Densitometric analysis of the images of scanned blots was performed using ImageJ (1.51j8) program.

\section{Immunofluorescence}

$1.5 \times 10^{5}$ cells were grown on glass coverslips (Fisher Scientific, USA) per well in 24-well plates and treated as indicated. For mitochondrion staining, live cells were incubated with $150 \mathrm{nM}$ MitoTracker Red CMXRos (Invitrogen, USA) for $30 \mathrm{~min}$, prior to fixation. Cells were fixed in 4\% PFA (Thermo Scientific, USA) at room temperature for $15 \mathrm{~min}$, permeabilized with $0.1 \%$ Triton X100 (Sigma, USA) prepared in 1XPBS and blocked for $1 \mathrm{~h}$ with $4 \%$ normal goat or donkey serum (Life technologies and Millipore, USA, respectively) depending on the corresponding secondary antibody. Cells were then incubated with appropriate primary antibodies, washed four times with 1XPBS for $5 \mathrm{~min}$ each and incubated with 1:250 Alexa Fluor 488 or 555 conjugated secondary antibodies (Life Technologies, USA) along with DAPI $(0.25 \mu \mathrm{g} / \mathrm{ml})$ (Invitrogen, USA). After washing with 1XPBS 3 times, coverslips were mounted on glass slides using ProLong Gold antifade reagent (Molecular Probes, USA). Fluorescent images were captured using either AxioObserver. Z1 microscope (Carl Zeiss, Germany) at $\times 40$ (NA: 1.4) objective using the ZEN2 imaging program. Confocal images were acquired using WaveFx spinning-disk microscope (Quorum Technologies, ON, Canada) using $\times 20$ (NA: 0.85 ) or $\times 100$ (NA: 1.4) oil immersion objectives using EM-CDD camera (Hamamatsu, Japan) and Volocity software (PerkinElmer, USA) setup on Olympus IX-81 inverted stand (Olympus, Japan). Brightness and contrast 
adjustments on the images were evenly applied for better visual presentation.

\section{Cell-viability assay}

Cell viability was measured using PI exclusion assay as follows. Briefly, $1.5 \times 10^{5}$ cells were plated per well in 12well plates followed by a 24 or $48 \mathrm{~h}$ Dox stimulation at the indicated Dox concentrations. STS $(2.5 \mu \mathrm{M})$ was used for $24 \mathrm{~h}$ as a positive control for inducing cell death. At the end of treatments, cells were harvested by trypsinization, washed twice with 1XPBS and resuspended in 1XPBS containing $0.5 \%$ BSA and $50 \mu \mathrm{g} / \mathrm{ml}$ of propidium iodide (Invitrogen, USA). Flow-cytometric analysis of 10,000 cells for three independent experiments was done using a BD-Accuri flow cytometer using the C6 software.

\section{Clonogenic survival assays}

Thousands cells were plated in 6-well dishes in triplicate and cultured for 12 days (8 days for MDA-MB-231). Fresh growth medium was supplied every 3 days. Colonies were stained with staining solution ( $0.4 \%$ Crystal violet, $4 \%$ PFA in 1XPBS), washed, dried overnight, and counted manually.

\section{Cell-count assays}

$1 \times 10^{5}$ MCF-7 Tet-On BIK or Empty vector cells were plated per well in 6-well plates in duplicates. The next day, doxycycline treatment was initiated. Fresh medium containing the appropriate concentration of doxycycline was supplemented every 3 days. At the time of harvest, the floating cell population was collected, cells were washed once with 1XPBS, trypsinized and counted using a hemocytometer in duplicates. Trypan blue negative cells were used for cell counts. Three independent experiments were performed.

\section{TMRE staining and flow cytometry}

$2 \times 10^{5}$ MDA-MB-231 cells were plated per well in 12 well cell-culture dishes and induced with $250 \mathrm{ng} / \mathrm{ml}$ Dox or treated with $2.5 \mu \mathrm{M}$ staurosporine for $24 \mathrm{~h}$. At the end of the treatments, growth medium containing floaters was collected, adherent cells were washed once with $1 \mathrm{~mL}$ 1XPBS and trypsinized with $50 \mu \mathrm{L}$ trypsin solution for $5 \mathrm{~min}$. Trypsin was neutralized with $1 \mathrm{~mL}$ complete growth medium and the cell suspension was spun down at $300 \times g$ for $5 \mathrm{~min}$. Resulting cell pellets were resuspended in $500 \mu \mathrm{L}$ growth medium and a $150 \mu \mathrm{L}$ aliquot from this was collected in V-bottom plates and centrifuged at $300 \times$ $g$ for $5 \mathrm{~min}$. The supernatant was discarded and cell pellets were resuspended in $200 \mu \mathrm{L}$ complete growth medium containing $0.1 \mu \mathrm{M}$ Tetramethylrhodamine ethyl ester (TMRE) solution followed by incubation at $37^{\circ} \mathrm{C}$ in cellculture incubator for $15 \mathrm{~min}$. Cells were spun down at $300 \times g$ for $5 \mathrm{~min}$, the supernatant discarded and pellets washed once with 1XPBS. The final cell pellets were resuspended in $250 \mu \mathrm{L}$ of $1 \mathrm{XPBS}$, and passed through a $70 \mu \mathrm{m}$ nylon sieve to remove any cell clumps. Flowcytometric analysis was performed on 10,000 cells using the BD-Accuri flow cytometer for at least three independent experiments. Data were analyzed using BDAccuri c6 program while representative histograms were prepared using Flow Jo (version $\mathrm{X}$ ) program.

\section{Active caspase- $3 / 7$ staining and flow cytometry}

$2.5 \times 10^{5}$ MDA-MB-231 cells were plated per well in 12 well cell-culture plates and induced with $250 \mathrm{ng} / \mathrm{ml} \mathrm{dox-}$ ycycline or staurosporine for $24 \mathrm{~h}$. Floating cells were collected and adherent cells were trypsinized $(50 \mu \mathrm{L})$, neutralized with $1 \mathrm{~mL}$ growth medium and spun down at $300 \times g$ for $5 \mathrm{~min}$. Resulting cell pellets were resuspended in $0.5 \mathrm{~mL}$ growth medium and $200 \mu \mathrm{L}$ of this cell suspension was spun down at $300 \times g$ for 5 min in V-bottom plates. The supernatant was discarded and the cell pellets were resuspended in $250 \mu \mathrm{L}$ growth medium containing $5 \mu \mathrm{M}$ Cell Event Green (Cat. No. C10723, Invitrogen, USA) reagent for $30 \mathrm{~min}$ in cell-culture incubator. Subsequently, cells were passed through a $70 \mu \mathrm{m}$ nylon sieve to get rid of clumps and flow-cytometric analysis was performed on at least 10,000 cells. Data were analyzed using BD-Accuri c6 program while representative histograms were prepared using Flow Jo (version $\mathrm{X}$ ) program.

\section{Fluorescence-activated cell sorting of mild and frank caspase-positive cells}

$2 \times 10^{5}$ MDA-MB-231 cells were stained with Cell Event Green reagent as described in the Active caspase-3/ 7 staining and flow cytometry. Thousands cells were sorted directly into 6-well plates containing $2 \mathrm{~mL}$ growth medium in duplicates for colony-formation assays while 100,000 cells were collected in a 50/50 mix of 1XPBS and FCS for western blot analysis.

\section{Quantitation of $\gamma \mathrm{H} 2 \mathrm{AX}$ foci and apoptotic nuclei}

Foci per nucleus image analysis were performed in MATLAB (MathWorks). For nuclei boundary detection, an Otsu based mask segmentation approach was used ${ }^{73}$, followed by separation of touching nuclei through watersheding. Incomplete nuclei (binary objects touching image edges) were removed and the resultant nuclei boundaries were manually verified. For foci detection, the background image was subtracted from the $\gamma \mathrm{H} 2 \mathrm{AX}$ raw images as earlier detailed ${ }^{73}$, using a 10-pixel wide Gaussian. Foci local intensity spots were then detected through iterative filtering from significant coefficients and binarized. The number of foci per nucleus was then computed from the nuclei and foci binary images. Cells with three foci or less were observed in untreated cells and represented basal background levels of $\gamma \mathrm{H} 2 \mathrm{AX}$ positivity. To 
quantitate discrete DNA damage by $\gamma \mathrm{H} 2 \mathrm{AX}$ immunofluorescence, we counted \% cells with 4-19 foci. Cells with $>19$ foci were not observed. For apoptotic cells identification, diffuse pan-nuclear $\gamma \mathrm{H} 2 \mathrm{AX}$ staining was segmented using the aforementioned nuclei boundary detection method. Resultant binary objects matching nucleus objects were considered apoptotic. A total of 19-20 frames were analyzed for each group.

\section{Alkaline comet assay}

Comet assay was performed as described previously ${ }^{11,74}$. The assay was performed under low light conditions to minimize light-induced DNA damage. Briefly, cells were harvested after appropriate treatments by trypsinization followed by centrifugation $\left(230 \times g\right.$ at $\left.4{ }^{\circ} \mathrm{C}\right)$ and resuspended in $1 \mathrm{XPBS}$. Cells were resuspended in $1 \%$ low melting point agarose (LMP) at a density of 50 cells $/ \mu \mathrm{L}$; $50 \mathrm{uL}$ of this agarose was put on glass slides (precoated with 1\% LMP agarose) and was allowed to bond with the coated agarose for $30 \mathrm{~min}$ at $4{ }^{\circ} \mathrm{C}$. Next, agaroseembedded cells were subjected to in situ lysis in lysis buffer $(2.5 \mathrm{M} \mathrm{NaCl}, 100 \mathrm{mM}$ EDTA, $10 \mathrm{mM}$ Trizma base, $1 \% \mathrm{TX}-100, \mathrm{pH} 10)$ at $4{ }^{\circ} \mathrm{C}$ for $60 \mathrm{~min}$. Subsequently, nuclear DNA was unwound using freshly prepared alkaline unwinding solution $(200 \mathrm{mM} \mathrm{NaOH}, 1 \mathrm{mM}$ EDTA, $\mathrm{pH} \mathrm{8)} \mathrm{for} 1 \mathrm{~h}$ at $4{ }^{\circ} \mathrm{C}$. Subsequently, slides were aligned equidistance from the electrodes and electrophoresis was performed at $300 \mathrm{~mA}$ for $30 \mathrm{~min}$ in alkaline electrophoresis solution $(200 \mathrm{mM} \mathrm{NaOH}, 1 \mathrm{mM}$ EDTA, $\mathrm{pH}>13)$. Next, the slides were washed with $\mathrm{dH}_{2} \mathrm{O}$ twice followed by $70 \%$ ethanol fixation and drying. Electrophoresed DNA was stained with RedSafe DNA stain. Resulting comets were imaged using AxioObserver.Z1 microscope (Carl Zeiss, Germany) at $\times 10$ magnification. $\% \mathrm{DNA}$ in the tail was calculated using CasPLab comet analysis program (http://casplab.com/download) ${ }^{75}$.

\section{siRNA transfections}

$2 \times 10^{5}$ cells were seeded per well in 12 -well plates. The next day, $100 \mathrm{nM}$ siRNA oligos were transfected using Lipofectamine 2000 as per manufacturer's instructions. Knockdown of Dox-induced Bik was performed by transfecting previously reported anti-Bik siRNA $24 \mathrm{~h}$ in advance followed by Dox induction for $24 \mathrm{~h}^{27}$. CAD silencing was performed in a similar manner. Details of the siRNA oligos used in the study are described in Supplementary Table 2.

\section{Measurement of ROS levels and DNA damage}

Cells were incubated in growth medium containing $2.5 \mu \mathrm{M}$ CellRox Green reagent (Invitrogen, USA) for $30 \mathrm{~min}$ at $37^{\circ} \mathrm{C}$. ROS levels were quantitated by measuring Mean Fluorescence Intensity (MFI) in individual cells using flow-cytometric analysis on a BD-Accuri flow cytometer using the C6 software. TBHP (tert-butyl hydroperoxide, $100 \mu \mathrm{M})(458149$, Sigma, USA) was used as positive control. $2.5 \mathrm{mM}$ NAC ( $\mathrm{N}$-acetylcysteine) (A9165, Sigma, USA) was used as a ROS scavenger for 30 min prior to TBHP treatment. ROS dependent DNA damage was measured by treating cells with $50 \mu \mathrm{M} \mathrm{H}_{2} \mathrm{O}_{2}$ for $30 \mathrm{~min}$ in the presence or absence of caspase inhibitor z-VAD-fmk (Promega, USA) or ROS scavenger NAC. The DNA damage was confirmed using western blotting with the anti- $\gamma \mathrm{H} 2 \mathrm{AX}$ antibody.

\section{CaspACE staining and flow cytometry}

$2 \times 10^{5}$ cells/well were seeded in 12 -well plates. Twentyfour hour later, cells were treated with the indicated concentrations of dox or staurosporine $(2.5 \mu \mathrm{M})$ for $24 \mathrm{~h}$. At the end of the treatments, floating cells were collected followed by trypsinization $(50 \mu \mathrm{L})$ to collect the adherent cell population. Trypsin was neutralized using $1 \mathrm{~mL}$ of growth medium. Tubes containing cell suspension were spun at $300 \times g$ for $5 \mathrm{~min}$ at room temperature. Cell pellets were resuspended in $450 \mu \mathrm{L}$ growth medium and a $175 \mu \mathrm{L}$ aliquot was transferred to 96-well V-bottom plates followed by spinning at $300 \times g$ for $5 \mathrm{~min}$ at room temperature. Resulting cell pellets were resuspended in $200 \mu \mathrm{L}$ growth medium containing $10 \mu \mathrm{M}$ CaspAce reagent (\#G7461, Promega, USA) or just growth medium for unstained control and incubated in the cell-culture incubator for $1 \mathrm{~h}$. V-bottom plates were spun for $5 \mathrm{~min}$ at $300 \times g$ and cell pellets were washed twice with $200 \mu \mathrm{L}$ $0.5 \%$ BSA containing 1 XPBS followed by final resuspension in $200 \mu \mathrm{L} 0.5 \%$ BSA containing 1XPBS. Flow cytometry was performed on a BD-Accuri flow cytometer on the FL-1 channel. For dox-induced cells, at least 10,000 cells while for staurosporine-treated cells 5000 cells were acquired for three independent experiments. Data analysis was performed on FlowJo program_V10.

\section{Single-cell migration assays}

MCF-7 LTC or MDA-MB-231 LTC cells were seeded at a density of 3000 cells/well in 8-well LabTek glass-bottom chambers (\#155409, Thermo Fisher Scientific, USA). The following day, live-cell imaging extending up to $24 \mathrm{~h}$ was initiated on a ZEN AxioObserver microscope equipped with a heated and humidified stage. Time-lapse images were acquired every $1 \mathrm{~h}$ using a 10x objective and Rolera camera. Post-acquisition analysis of single-cell tracks was performed manually on cells that did not undergo cell division using the ImageJ program. Speed was calculated by dividing track length at each time point divided by elapsed time (hours). Rose plots and persistence were computed using the MATLAB program. Persistence was calculated by dividing displacement with track length. Confined and nonconfined classification was determined from individual track mean square displacement curve fit 
alpha, with alpha values $<1$ corresponding to confined motion. From three independent experiments, at least 57 and 60 tracks were analyzed in MCF-7 LTC and MDAMB-231 LTC cells, respectively.

\section{Collective cell migration assays}

$2.5 \times 10^{5}$ MCF-7 or MDA-MB-231 LTC cells were seeded in 8-well LabTek glass-bottom chambers (\#155409, Thermo Fisher Scientific, USA) to obtain a confluent monolayer the following day. Cells were treated with $10 \mu \mathrm{g} / \mathrm{ml}$ mitomycin C (\#M4287, Sigma, USA) for $3 \mathrm{~h}$ to block cell proliferation. Subsequently, horizontal scratches were made using a $200 \mu \mathrm{L}$ pipette tip in one swift motion. Cell debris and mitomycin $C$ were washed away by three gentle washes with growth medium. Subsequently, live-cell imaging extending up to $15 \mathrm{~h}$ was initiated on a ZEN AxioObserver microscope equipped with a heated and humidified stage. Time-lapse images were acquired every $1 \mathrm{~h}$ using a $\times 10$ objective and Rolera camera. Three different scratch positions per cell line were selected per experiment. Area covered by cells was deducted from the initial area to obtain distance traveled over time using ZEN pro imaging program. At least three independent experiments were performed.

\section{Soft-agar colony formation}

Soft-agar colony formation was done as described previously $^{11,76}$. Briefly, 2500 cells were resuspended in $0.35 \%$ agarose (Invitrogen, USA) mixed with complete growth medium and layered on top of a $1 \%$ agarose: growth medium mix. Colonies were allowed to form for 7 weeks (6 weeks for MDA-MB-231 LTC) and the agarose layer was kept hydrated by addition of $200 \mu \mathrm{L}$ of growth medium (RPMI $+10 \%$ FCS) every 5 days. Colonies were stained with $0.005 \%$ crystal violet (Fisher science education, USA) solution overnight followed by imaging using an EPSON scanner. Soft-agar colonies formed by MDA-MB-231 LTC cells were difficult to visualize on the EPSON scanner. Therefore, representative images were captured using a ZEN AxioObserver microscope on a $\times 10$ objective.

\section{Mammosphere formation assay}

Low cell attachment plates were prepared by incubating 24-well plates with $0.5 \mathrm{ml}$ of $20 \mathrm{mg} / \mathrm{ml}$ poly-HEMA (Sigma, USA) solution prepared in $95 \% \mathrm{EtOH}$ followed by overnight evaporation in the cell-culture hood. EVLTC-250, BIK-LTC-0, and BIK-LTC-250 single cells were plated in replicate in poly-HEMA coated 24-well plates at 5 cells $/ \mathrm{mm}^{3}$ suspension $(500 \mu \mathrm{l}$ suspension volume per well) in DMEM/F12 (1:1) supplemented with $20 \mathrm{ng} / \mathrm{mL}$ FGF-2 (Sigma, USA), 20 ng/mL EGF (PeproTech), 2\% B27 without vitamin A (GIBCO, USA) and $1 \times$ ITS (insulintransferrin-selenium, GIBCO). $0.5 \%$ Methylcellulose (Sigma, USA) was used to prevent cell aggregation, allowing the growth of mammospheres in different zplanes of the medium. Every 3 days, $500 \mu$ of fresh medium was added to each well without removing the old medium. Mammospheres were imaged in brightfield (Zeiss AxioObserver.Z1 Microscope) on days 4, 8, and 12 (on day 28 for MDA-MB-231 LTC). Mammosphere formation efficiency was determined on day 12 (day 28 for MDA-MB-231 LTC) and was calculated from the number of spheres per well, divided by the number of cells plated, multiplied by 100 (to convert it to percentage).

\section{Mammospheres brightfield images segmentation}

Image analyses were performed in MATLAB (MathWorks). To segment mammospheres in brightfield images and determine their areas, a binary gradient image mask of the mammosphere(s) was calculated from a threshold value determined by edge and Sobel operator. Linear gaps in the gradient images were dilated using linear structuring elements, interior holes filled, and resultant mammosphere boundary smoothened by eroding the image twice with a diamond structuring element. Manual inspection of each image was done to ensure correct boundary detection.

\section{Antiestrogen treatment}

Tamoxifen (T5648, Sigma) was dissolved in DMSO at a stock concentration of $1 \mathrm{mM}$. The experiment was performed under low light conditions to minimize changes in the chirality of Tamoxifen. MCF-7 cells were grown in phenol red-free RPMI $+10 \%$ FCS medium and treated with Tamoxifen at the indicated concentrations for $72 \mathrm{~h}$. Cell lysates were prepared in RIPA buffer (50 mM Tris-cl, $150 \mathrm{mM} \mathrm{NaCl}, 0.1 \%$ SDS, 1\% NP-40, 0.5\% deoxycholate, and $1 \mathrm{mM}$ EDTA, pH 7.5) supplemented with protease(11873580001, Roche, USA) and phosphatase inhibitors (04906837001, Roche, USA), and BIK expression was confirmed using western blotting.

\section{Gene Microarray datasets}

ER-positive, tamoxifen-treated datasets include GSE $17705^{43}$ and GSE2990 ${ }^{42}$. For these datasets, raw data were downloaded, background adjusted and median normalized using the Robust Multi-array Average (RMA) procedure in MATLAB Bioinformatics Toolbox. Original normalized TNBC datasets were downloaded and include GSE31519 ${ }^{50}$, GSE33926 ${ }^{44}$, and GSE65194 ${ }^{45-47}$. To dichotomize patients into BIK-low and BIK-high groups, an optimum cut point was determined for each dataset by receiver operator characteristic (ROC) curve analysis with disease recurrence as a classification variable following the approach described by ${ }^{77}$ using MedCalc version 15 (Ostend, Belgium). Disease-free survival was calculated by the Kaplan-Meier (KM) analysis. Significant differences between KM curves were measured by the log-rank test. 


\section{Tissue-microarray analysis}

Tissue-microarrays (TMA) were prepared as described previously $(n=152)^{15}$. Patient information was collected under research ethics board approval (HREB Biomedical). ER-positive patients were identified by immunohistochemical analysis of tumor biopsies. Immunostaining of the TMAs was performed using an anti-BIK antibody (Santa Cruz Biotechnology, Inc. USA). Scoring of the immunostained TMA was performed in an outcome blinded fashion according to training and guidelines from the study's breast pathologist. An optimum score cut point was determined by performing ROC curve analysis where disease recurrence was used as a classification variable. Disease-free and overall survival curves were prepared using MedCalc version 15 (Ostend, Belgium). Significant differences between KM curves were measured by the log-rank test.

\section{Statistical analysis}

All bar and line graphs were prepared using GraphPad Prism version 7.03 (GraphPad Software, USA, www. graphpad.com). Statistical significance between two groups was determined using a two-tailed unpaired $t$-test where the alpha was set at 0.05 . To determine statistical significance among more than two groups of data, a oneway analysis of variance (ANOVA) was used. Where ANOVA was significant, differences between the two selected groups were analyzed by Sidak's post-hoc test, and $p$-values were obtained. Following ANOVA where every mean was compared with every other mean, $p$ values were calculated using Tukey's post-hoc test, whereas where every mean was compared to control mean, $p$-values were calculated using Dunnett's post-hoc test. Slopes of lines for collective cell migration of LTC cells were calculated by linear regression analysis, and statistical significance was determined using GraphPad Prism version 7.03 (GraphPad Software, USA, www. graphpad.com). (" $\left.p<0.05,{ }^{* * *} p<0.01,{ }^{* * * * *} p<0.001\right)$. If no statistical significance was found among the groups analyzed, no asterisks $(*)$ were shown.

\footnotetext{
Acknowledgements

Operating grants from the Alberta Institute for Health Research (AlHS)/Pfizer program (ISG, JRM), Alberta Cancer Foundation (ISG, JM) and Canadian Breast Cancer Foundation (CBCF) Prairies/ NWT Chapter (ISG) supported this research. S.D. received operating grants from the Canadian Breast Cancer Foundation (CBCF) Prairies/NWT Chapter. J.M. received operating grants from the Alberta Breast Cancer Initiatives program. Cell sorting experiments were performed at the University of Alberta Faculty of Medicine \& Dentistry Flow Cytometry Facility, which receives financial support from the Faculty of Medicine \& Dentistry and Canada Foundation for Innovation (CFI) awards to contributing investigators. Confocal imaging experiments were performed at the University of Alberta Faculty of Medicine \& Dentistry Cell Imaging Centre, which receives financial support from the Faculty of Medicine \& Dentistry, CFI and the Department of Medical Microbiology and Immunology, and awards to contributing investigators. We thank all members of the Goping lab for helpful discussions.
}

\section{Author details}

${ }^{1}$ Department of Biochemistry, University of Alberta, Edmonton, AB T6G 2H7, Canada. 'Department of Lab Medicine and Pathology, University of Alberta, Edmonton, AB T6G 2H7, Canada. ${ }^{3}$ Department of Surgery, University of Alberta, Edmonton, AB T6G 2H7, Canada. ${ }^{4}$ Department of Oncology, University of Alberta, Edmonton, AB T6G 2H7, Canada

\section{Conflict of interest}

The authors declare that they have no conflict of interest.

\section{Publisher's note}

Springer Nature remains neutral with regard to jurisdictional claims in published maps and institutional affiliations.

Supplementary Information accompanies this paper at (https://doi.org/ 10.1038/s41419-020-2654-2).

Received: 7 October 2019 Revised: 16 May 2020 Accepted: 18 May 2020 Published online: 11 June 2020

\section{References}

1. Tsujimoto, Y., Cossman, J., Jaffe, E. \& Croce, C. M. Involvement of the bcl-2 gene in human follicular lymphoma. Science 228, 1440-1443 (1985).

2. Vaux, D. L., Cory, S. \& Adams, J. M. Bcl-2 gene promotes haemopoietic cell survival and cooperates with c-myc to immortalize pre-B cells. Nature $\mathbf{3 3 5}$, 440-442 (1988).

3. Billard, C. BH3 mimetics: status of the field and new developments. Mol. Cancer Ther. 12, 1691-1700 (2013).

4. Delbridge, A. R. \& Strasser, A. The BCL-2 protein family, BH3-mimetics and cancer therapy. Cell Death Differ. 22, 1071-1080 (2015).

5. Roberts, A. W. et al. Targeting BCL2 with venetoclax in relapsed chronic lymphocytic leukemia. N. Engl. J. Med. 374, 311-322 (2016).

6. Berardo, M. D. et al. bcl-2 and apoptosis in lymph node positive breast carcinoma. Cancer 82, 1296-1302 (1998).

7. Vargas-Roig, L. M. et al. Prognostic value of $\mathrm{BCl}-2$ in breast cancer patients treated with neoadjuvant anthracycline based chemotherapy. Mol. Oncol. 2, 102-111 (2008).

8. Neri, A. et al. Bcl-2 expression correlates with lymphovascular invasion and long-term prognosis in breast cancer. Breast Cancer Res. Treat. 99, 77-83 (2006).

9. Ichim, G. \& Tait, S. W. A fate worse than death: apoptosis as an oncogenic process. Nat. Rev. Cancer 16, 539-548 (2016).

10. Ichim, G. et al. Limited mitochondrial permeabilization causes DNA damage and genomic instability in the absence of cell death. Mol. Cell 57, 860-872 (2015).

11. Liu, X. et al. Caspase-3 promotes genetic instability and carcinogenesis. Mol. Cell 58, 284-296 (2015).

12. Miles, M. A. \& Hawkins, C. J. Executioner caspases and CAD are essential for mutagenesis induced by TRAll or vincristine. Cell Death Dis. 8, e3062 (2017).

13. Cartwright, I. M., Liu, X., Zhou, M., Li, F. \& Li, C. Y. Essential roles of Caspase-3 in facilitating Myc-induced genetic instability and carcinogenesis. elife https:/doi. org/10.7554/eLife.26371 (2017).

14. Larsen, B. D. \& Sorensen, C. S. The caspase-activated DNase: apoptosis and beyond. FEBS J. 284, 1160-1170 (2017).

15. Pandya, $\mathrm{V}$. et al. The pro-apoptotic paradox: the $\mathrm{BH}$-only protein $\mathrm{BCl}-2$ interacting killer (Bik) is prognostic for unfavorable outcomes in breast cancer. Oncotarget 7, 33272-33285 (2016).

16. Hur, J. et al. The Bik BH3-only protein is induced in estrogen-starved and antiestrogen-exposed breast cancer cells and provokes apoptosis. Proc. Natl Acad. Sci. USA 101, 2351-2356 (2004).

17. Hur, J. et al. Regulation of expression of BIK proapoptotic protein in human breast cancer cells: p53-dependent induction of BIK mRNA by fulvestrant and proteasomal degradation of BIK protein. Cancer Res. 66, 10153-10161 (2006).

18. Coser, K. R. et al. Global analysis of ligand sensitivity of estrogen inducible and suppressible genes in MCF7/BUS breast cancer cells by DNA microarray. Proc. Natl Acad. Sci. USA 100, 13994-13999 (2003).

19. Chinnadurai, G., Vijayalingam, S. \& Rashmi, R. BIK, the founding member of the $\mathrm{BH} 3$-only family proteins: mechanisms of cell death and role in cancer and pathogenic processes. Oncogene 27, S20-\$29 (2008). 
20. Spender, L. C. et al. TGF-beta induces apoptosis in human B cells by transcriptional regulation of BIK and BCL-XL. Cell Death Differ. 16, 593-602 (2009).

21. Real, P. J. et al. Transcriptional activation of the proapoptotic bik gene by E2F proteins in cancer cells. FEBS Lett. 580, 5905-5909 (2006)

22. Ritchie, A., Gutierrez, O. \& Fernandez-Luna, J. L. PAR bZIP-bik is a novel transcriptional pathway that mediates oxidative stress-induced apoptosis in fibroblasts. Cell Death Differ. 16, 838-846 (2009).

23. Bodet, $\mathrm{L}$. et al. $\mathrm{BH} 3$-only protein Bik is involved in both apoptosis induction and sensitivity to oxidative stress in multiple myeloma. Br. J. Cancer 103, 1808-1814 (2010).

24. Mebratu, Y. A., Dickey, B. F., Evans, C. \& Tesfaigzi, Y. The BH3-only protein Bik/ Blk/Nbk inhibits nuclear translocation of activated ERK $1 / 2$ to mediate IFNgamma-induced cell death. J. Cell Biol. 183, 429-439 (2008).

25. Koong, A. C. et al. Candidate genes for the hypoxic tumor phenotype. Cancer Res. 60, 883-887 (2000).

26. Kagawa, S. et al. Deficiency of caspase-3 in MCF7 cells blocks Bax-mediated nuclear fragmentation but not cell death. Clin. Cancer Res. 7, 1474-1480 (2001).

27. Mathai, J. P., Germain, M. \& Shore, G. C. BH3-only BIK regulates BAX,BAKdependent release of $\mathrm{Ca} 2+$ from endoplasmic reticulum stores and mitochondrial apoptosis during stress-induced cell death. J. Biol. Chem. 280, 23829-23836 (2005).

28. Germain, M., Mathai, J. P., McBride, H. M. \& Shore, G. C. Endoplasmic reticulum BIK initiates DRP1-regulated remodelling of mitochondrial cristae during apoptosis. EMBO J. 24, 1546-1556 (2005).

29. Solier, S. \& Pommier, Y. The nuclear gamma-H2AX apoptotic ring: implications for cancers and autoimmune diseases. Cell Mol. Life Sci. 71, 2289-2297 (2014).

30. Elangovan, B. \& Chinnadurai, G. Functional dissection of the pro-apoptotic protein Bik. Heterodimerization with anti-apoptosis proteins is insufficient for induction of cell death. J. Biol. Chem. 272, 24494-24498 (1997).

31. Fu, Y., Li, J. \& Lee, A. S. GRP78/BiP inhibits endoplasmic reticulum BIK and protects human breast cancer cells against estrogen starvation-induced apoptosis. Cancer Res. 67, 3734-3740 (2007)

32. Zhou, H., Zhang, Y., Fu, Y., Chan, L. \& Lee, A. S. Novel mechanism of antiapoptotic function of 78-kDa glucose-regulated protein (GRP78): endocrine resistance factor in breast cancer, through release of B-cell lymphoma 2 (BCL2) from BCL-2-interacting killer (BIK). J. Biol. Chem. 286, 25687-25696 (2011).

33. Dubrovska, A. et al. CXCR4 activation maintains a stem cell population in tamoxifen-resistant breast cancer cells through AhR signalling. Br. J. Cancer 107, 43-52 (2012)

34. Morata-Tarifa, C. et al. Validation of suitable normalizers for miR expression patterns analysis covering tumour heterogeneity. Sci. Rep. 7, 39782 (2017).

35. Zhang, L., Xu, L., Zhang, F. \& Vlashi, E. Doxycycline inhibits the cancer stem cell phenotype and epithelial-to-mesenchymal transition in breast cancer. Cell Cycle 16, 737-745 (2017).

36. Vieira, A. F. et al. P-cadherin signals through the laminin receptor alpha6beta4 integrin to induce stem cell and invasive properties in basal-like breast cancer cells. Oncotarget 5, 679-692 (2014).

37. Grimshaw, M. J. et al. Mammosphere culture of metastatic breast cancer cells enriches for tumorigenic breast cancer cells. Breast Cancer Res. 10, R52 (2008).

38. Liu, Y. et al. Lack of correlation of stem cell markers in breast cancer stem cells. Br. J. Cancer 110, 2063-2071 (2014).

39. Rappa, G. et al. Growth of cancer cell lines under stem cell-like conditions has the potential to unveil therapeutic targets. Exp. Cell Res. 314, 2110-2122 (2008).

40. Wahler, J. et al. Vitamin D compounds reduce mammosphere formation and decrease expression of putative stem cell markers in breast cancer. J. Steroid Biochem. Mol. Biol. 148, 148-155 (2015).

41. Wang, R. et al. Comparison of mammosphere formation from breast cancer cell lines and primary breast tumors. J. Thorac. Dis. 6, 829-837 (2014).

42. Sotiriou, C. et al. Gene expression profiling in breast cancer: understanding the molecular basis of histologic grade to improve prognosis. J. Natl Cancer Inst. 98, 262-272 (2006).

43. Symmans, W. F. et al. Genomic index of sensitivity to endocrine therapy for breast cancer. J. Clin. Oncol. 28, 4111-4119 (2010).

44. Kuo, W. H. et al. Molecular characteristics and metastasis predictor genes of triple-negative breast cancer: a clinical study of triple-negative breast carcinomas. PLOS ONE 7, e45831 (2012).

45. Maubant, S. et al. Transcriptome analysis of Wnt3a-treated triple-negative breast cancer cells. PLOS ONE 10, e0122333 (2015).

46. Maire, $V$. et al. TTK/hMPS1 is an attractive therapeutic target for triple-negative breast cancer. PLOS ONE 8, e63712 (2013).
47. Maire, V. et al. Polo-like kinase 1: a potential therapeutic option in combination with conventional chemotherapy for the management of patients with triplenegative breast cancer. Cancer Res. 73, 813-823 (2013).

48. Carey, L. A. et al. Race, breast cancer subtypes, and survival in the Carolina Breast Cancer Study. JAMA 295, 2492-2502 (2006).

49. Bertheau, P. et al. p53 in breast cancer subtypes and new insights into response to chemotherapy. Breast 22, S27-S29 (2013).

50. Rody, A. et al. A clinically relevant gene signature in triple negative and basallike breast cancer. Breast Cancer Res. 13, R97 (2011).

51. Zhao, $X$. et al. The endoplasmic reticulum (ER)-target protein Bik induces Hep3B cells apoptosis by the depletion of the ER Ca2+ stores. Mol. Cell Biochem. 312, 33-38 (2008).

52. Oppermann, M. et al. Caspase-independent induction of apoptosis in human melanoma cells by the proapoptotic Bcl-2-related protein Nbk/Bik. Oncogene 24, 7369-7380 (2005).

53. Naumann, U. et al. Adenoviral natural born killer gene therapy for malignant glioma. Hum. Gene Ther. 14, 1235-1246 (2003).

54. Mebratu, Y. A. et al. Bik reduces hyperplastic cells by increasing Bak and activating DAPk1 to juxtapose ER and mitochondria. Nat. Commun. 8, 803 (2017).

55. Mathai, J. P., Germain, M., Marcellus, R. C. \& Shore, G. C. Induction and endoplasmic reticulum location of BIK/NBK in response to apoptotic signaling by E1A and p53. Oncogene 21, 2534-2544 (2002).

56. Rashmi, R., Pillai, S. G., Vijayalingam, S., Ryerse, J. \& Chinnadurai, G. BH3-only protein BIK induces caspase-independent cell death with autophagic features in BCl-2 null cells. Oncogene 27, 1366-1375 (2008).

57. Gillissen, B. et al. Mcl-1 determines the Bax dependency of Nbk/Bik-induced apoptosis. J. Cell Biol. 179, 701-715 (2007).

58. Meterissian, $\mathrm{S}$. H. et al. Bcl-2 is a useful prognostic marker in Dukes' B colon cancer. Ann. Surg. Oncol. 8, 533-537 (2001).

59. Biswas, S., Shi, Q., Wernick, A., Aiello, A. \& Zinkel, S. S. The loss of the BH3-only Bcl-2 family member Bid delays T-cell leukemogenesis in Atm-/- mice. Cell Death Differ. 20, 869-877 (2013).

60. Labi, V. et al. Apoptosis of leukocytes triggered by acute DNA damage promotes lymphoma formation. Genes Dev. 24, 1602-1607 (2010).

61. Michalak, E. M. et al. Apoptosis-promoted tumorigenesis: gamma-irradiationinduced thymic lymphomagenesis requires Puma-driven leukocyte death Genes Dev. 24, 1608-1613 (2010)

62. Tomita, M. et al. Prognostic significance of bcl-2 expression in resected pN2 non-small cell lung cancer. Eur. J. Surg. Oncol. 29, 654-657 (2003).

63. Sun, G. et al. A molecular signature for anastasis, recovery from the brink of apoptotic cell death. J. Cell Biol. 216, 3355-3368 (2017).

64. Tang, H. L. et al. Cell survival, DNA damage, and oncogenic transformation after a transient and reversible apoptotic response. Mol. Biol. Cell 23, 2240-2252 (2012).

65. Lovric, M. M. \& Hawkins, C. J. TRAIL treatment provokes mutations in surviving cells. Oncogene 29, 5048-5060 (2010).

66. Haricharan, S., Bainbridge, M. N., Scheet, P. \& Brown, P. H. Somatic mutation load of estrogen receptor-positive breast tumors predicts overall survival: an analysis of genome sequence data. Breast Cancer Res. Treat. 146, 211-220 (2014).

67. Soteriou, D. \& Fuchs, Y. A matter of life and death: stem cell survival in tissue regeneration and tumour formation. Nat. Rev. Cancer 18, 187-201 (2018).

68. Huang, Q. et al. Caspase 3-mediated stimulation of tumor cell repopulation during cancer radiotherapy. Nat. Med. 17, 860-866 (2011).

69. Bondar, T. \& Medzhitov, R. p53-mediated hematopoietic stem and progenitor cell competition. Cell Stem Cell 6, 309-322 (2010).

70. Noy, R. \& Pollard, J. W. Tumor-associated macrophages: from mechanisms to therapy. Immunity 41, 49-61 (2014).

71. Ford, C. A. et al. Oncogenic properties of apoptotic tumor cells in aggressive B cell lymphoma. Curr. Biol. 25, 577-588 (2015).

72. Coser, K. R. et al. Antiestrogen-resistant subclones of MCF-7 human breast cancer cells are derived from a common monoclonal drug-resistant progenitor. Proc. Natl Acad. Sci. USA 106, 14536-14541 (2009).

73. Githaka, J. M. et al. Ligand-induced growth and compaction of CD36 nanoclusters enriched in Fyn induces Fyn signaling. J. Cell Sci. 129, 4175-4189 (2016).

74. Singh, N. P., McCoy, M. T., Tice, R. R. \& Schneider, E. L. A simple technique for quantitation of low levels of DNA damage in individual cells. Exp. Cell Res. 175, 184-191 (1988). 
75. Konca, K. et al. A cross-platform public domain PC image-analysis program for the comet assay. Mutat. Res. 534, 15-20 (2003).

76. Borowicz, S. et al. The soft agar colony formation assay. J. Vis. Exp. https://doi. org/10.3791/51998 (2014).
77. DeLong, E. R., DeLong, D. M. \& Clarke-Pearson, D. L. Comparing the areas under two or more correlated receiver operating characteristic curves: a nonparametric approach. Biometrics 44, 837-845 (1988). 